\title{
The ancestry and cumulative evolution of immune reactions
}

\author{
Jolanta M. Dzik ${ }^{凶}$ \\ Nencki Institute of Experimental Biology, Polish Academy of Sciences, and Department of Biochemistry, Faculty of Agriculture and Biology, \\ Warsaw University of Life Sciences - SGGW, Warszawa, Poland
}

The last two decades of study enriched greatly our knowledge of how the immune system originated and the sophisticated immune mechanisms of today's vertebrates and invertebrates developed. Even unicellular organisms possess mechanisms for pathogen destruction and self recognition. The ability to distinguish self from non-self is a prerequisite for recognition of sexual compatibility and ensuring survival. Molecules involved in these processes resemble those found in the phagocytic cells of higher organisms. Recognition of bacteria by scavenger receptors induces phagocytosis or endocytosis. The phagocytic mechanisms characterizing the amoeboid protozoans developed further during the evolution towards innate immunity. The scavenger receptor cysteine-rich domain SRCR is encoded in the genomes from the most primitive sponges to mammals. The immune system of sponges comprises signal transduction molecules which occur in higher metazoans as well. Sponges already possess recognition systems for pathogenic bacteria and fungi, based on membrane receptors (a lipopolysaccharide-interacting protein, a cell surface receptor recognizing $\beta(1 \rightarrow 3)$-D-glucans of fungi). Perforin-like molecules and lysozymes are involved, among others, in defense in sponges. Reactive oxygen and nitrogen species function in the immunity of early metazoan. Genes encoding the family of reactive oxygen-generating NADPH oxidases (Noxes) are found in a variety of protists and plants. The NO synthases of cnidarians, mollusks, and chordates are conserved with respect to the mammalian NOS. The antimicrobial peptides of protozoans, amoebapores, are structural and functional analogs of the natural killer cell peptide, NK-lysin, of vertebrates. An ancestral S-type lectin has been found in sponges. Opsonizing properties of lectins and the ability to agglutinate cells justify their classification as primitive recognition molecules. Invertebrate cytokines are not homologous to those of vertebrate, and their functional convergence was presumably enabled by the general similarity of the lectin-like recognition domain three-dimensional structure. Sponges contain molecules with SCR/CCP domains that show high homology to the mammalian regulators of complement activation (RCA family). A multi-component complement system comprising at least the central molecule of the complement system, C3, Factor B, and MASP developed in the cnidarians and evolved into the multilevel cascade engaged in innate and acquired immunity of vertebrates. The adaptive immune system of mammals is also deeply rooted in the metazoan evolution. Some its precursors have been traced as deep as in sponges, namely, two classes of receptors that comprise Ig-like domains, the receptor tyrosine kinases (RTK), and the non-enzymic sponge adhesion molecules (SAM). The antibody-based immune system defined by the presence of the major histocompatibility complex (MHC), T-cell receptor (TCR), $\mathrm{B}$-cell receptor (BCR) or recombination activating genes (RAGs) is known beginning from jawed fishes. However, genes closely resembling RAG1 and RAG2 have been uncovered in the genome of a see urchin. The ancestry of MHC gene remains unknown. Similarly, no homologue of the protein binding domain (PBD) in MHC molecules has been found in invertebrates. The pathway by which endogenous peptides are degraded for presentation with class I MHC molecules utilizes mechanisms similar to those involved in the normal turnover of intracellular proteins, apparently recruited to work also for the immune system. Several cDNAs coding for lysosomal enzymes, e.g., cathepsin, have been isolated from sponges. All chromosomal duplication events in the MHC region occurred after the origin of the agnathans but before the gnathostomes split from them. The V-domains of the subtype found in the receptors of $T$ and B-cells are known from both agnathans and cephalochordates, although they do not rearrange. The rearrangement mechanism of the lymphocyte V-domains suggests its origin from a common ancestral domain existing before the divergence of the extant gnathostome classes. Activationinduced deaminase (AID) - homologous proteins have been found only in the gnathostomes. It appears thus that the adaptive immunity of vertebrates is a result of stepwise accumulation of small changes in molecules, cells and organs over almost half a billion years.

Keywords: antibody-based immunity, antigen presentation, complement, cytokines, evolution, innate immunity, invertebrates, nitric oxide, phagocytosis, protoza, receptors, signal transduction, sponges, superoxide, vertebrates

Received: 02 April, 2010; revised: 16 August, 2010; accepted: 04 October, 2010; available on-line: 01 November, 2010

e-mail: jolanta_dzik@sggw.pl

Abbreviations: $\bar{A} B C$, ATP-binding cassette; $A B C B, A B C$ subgroup $B$; AID, activation-induced deaminase; AIF, allograf inflammatory fac tor; AIS, adaptive immune system; $B C R$; $B$-cell receptor; $B f$, factor $B$; $C C P$, complement control protein; CRD, carbohydrate recognition domain; $E G F$, epidermal growth factor; GRP, glucose-regulated protein; HLA; human leukocyte antigen; IFN, interferon; ILD, Ig-like domain; IRAK, interleukine receptor-associated kinase; LPS, lipopolysaccharide; LRR, leucine-rich repeats; MAC, membrane attack complex; MASP, MBL-associated serine protease; MBL, mannosebinding lectin; MHC, major histocompatibility complex; NK-lysin, natural killer cell-lysin; NOS, nitric oxide synthase; Nox, phagocyte NADPH oxidase; PLC, phospholipase C; PDB, protein-binding domain; PRR, pattern recognition receptor; PSMB; proteosome macropain subunit beta-type; RAG, recombination activating genes; RCA, regulators of complement activation; RTK, receptor tyrosine kinase; SCR, short consensus repeats; SRCR domain, scavenger receptor cysteine-rich domain; TAP; transporter-associated with antigen processing; TCR, T-cell receptor; TEP, thioester protein; TGF, tumor necrosis factor; TLR, Toll-like receptor 
Although immunology emerged as a modern science with the experiments on sea urchin embryos by Ilya I. Metschnikoff in 1882, and the role of B lymphocytes was recognized owing to physiological studies on the chicken bursa Fabricii by Bruce Glick in 1956, most what we know about immune reactions concerns mammals. This is because the main object of studies has been just a single vertebrate species, Homo sapiens. No wonder that for a long time it was considered self-evident that most of the complexity of immune mechanisms emerged quite recently, within the mammalian lineage. But this is hardly the case.

The immune system has developed in a stepwise way by progressive sophistication of basic functions that helped ancestral organisms to survive in their hostile environment. Even before developing the true immune mechanisms, they had to recognize their own body from the bodies of predators and parasites. Those exchanging genetic information had to develop an ability to recognize individuals of the same or different sex. This required reliable chemical sensors and routes of transferring information obtained by them to effectors acting in a way specific enough, different in respect to an enemy and to a mate.

The immune system responds to invasion using two crucial functions: sensors detect the invader, and elaborate response effectors attack it. The invader interacts with soluble or membrane-bound molecules of the host, capable of discriminating precisely between self (host) and non-self (pathogen). These molecular sensors recognize broad structural motifs (combination of sugars, certain proteins, particular lipid-bearing molecules, and some nucleic acid motifs) that are highly conserved within a microbial species but are generally absent from the host. Because they recognize particular overall molecular patterns, such receptors are called pattern recognition receptors (PRRs). The Toll-like receptors, belonging to PRRs, are the most important group of innate receptors which detect microbial products. Signals initiated at the TLRs of macrophages stimulate phagocytosis and production of chemical agents that are toxic to the phagocytosed microbes.

Detection of pathogen-associated molecular patterns by soluble or membrane-bound mediators of innate immunity triggers an action of multiple components of immunity. The soluble mediators include initiators of the complement system (mannose-binding lectin, C-reactive protein). The activation cascade of the complement leads to opsonization or lysis of the invaders. In addition, some of the byproducts of complement activation promote inflammation and thereby bring leukocytes to the sites of infection. Activated macrophages also secrete a class of molecules, known collectively as cytokines, that communicate via cell receptors to induce specific cell activities. For example, activated macrophages secrete cytokines such as IL-1, IL- 6 and TNF- $\alpha$, which induce and support inflammatory response. The cytokines released by cells involved in the innate response affect the nature of subsequent adaptive immune responses to the infection.

In vertebrates, antibodies and T-cell receptors, the sensors of adaptive immunity, recognize finer details of molecular structure. During the adaptive response, cytotoxic T-cells detect and destroy pathogens in the host's cells; wheareas antibodies produced by B-cell neutralize the capability of the invader to infect other cells. Moreover, antibodies (due to antibody-mediated uptake) increase the likelihood that the invader will be phagocytosed by macrophages and neutrophils. Antibodies also activate the complement system to bring about the lysis of microbes. After the infection is cleared, some of the $\mathrm{B}$ and T-cells will persist in the host in the form of memory $\mathrm{T}$ and memory B-cells. Further infections by the pathogen will then be met by a ready reserve of lymphocytes specific for the pathogen and capable of mounting a rapid response.

Below, an inferred sequence of events leading from the hypothetical simplest organisms able to mount immune reactions to the most advanced mammalian adaptive reactions is reviewed. Many of the ideas presented remain working hypotheses, requiring testing by more complete and reliable evidence. Research in this area is expanding steadily and this review is intended to be just an introduction to the extensive literature on the subject.

\section{ORIGIN OF SELF/NON-SELF RECOGNITION}

Without an ability to distinguish self from non-self no species of eukaryotic sexual organisms could survive, as this is a prerequisite to recognizing sexual compatibility. Moreover, this is the way to prevent feeding on individuals of the same species. Thus, the self/non-self mechanism is crucial not only for survival of individuals but also for speciation. This is achieved owing to specialized genomic regions that promote self/non-self interactions during sexual reproduction of eukaryotes. The sex-determining regions of the genome include mating type loci in protozoans and sex chromosomes in multicellular plants and animals. The mechanism of self/non-self recognition is known to function in the acrasid ,amoebae" Dictyostelium: the self recognition to avoid cannibalism is based on a species-specific receptor which is lacking in canibalistic strains (Waddell \& Duffy, 1986).

Since unicellular eukaryotes phagocytose for food and defense, phagocytosis is the most ancient and universal tool of defense against foreign material. Amoebae are distant relatives of the animals, but they already show mechanisms that allow recognition, internalization and destruction of foreign material. In fact, amoebae and macrophages share similar phagocytic mechanisms, e.g., prey-recognition by cell surface receptors (Allen \& Dawidowicz, 1990) and prey-killing by oxygen radicals (Davies et al., 1991). In the case of Dictyostelium phagocytosis, a heterotrimeric $G$ protein and phospholipase $\mathrm{C}$ are involved in cell signalling (references in Cardelli, 2001). Apparently, the phagocytic mechanisms characterizing the amoeboid protozoans were inherited during the evolution towards innate immunity (Sillo et al., 2008). Recently, it has been found that genes encoding carbohydrate-binding membrane proteins such as a gp138similar protein, a putative TIR-like domain (Toll/IL-1Rlike domain)-containing protein, a bystin-similar protein, or a tetraspanin family protein, are up-regulated during phagocytosis (Sillo et al., 2008). In mammalian cells tetraspanins are suggested to be involved in the early steps of phagocytosis (Little et al., 2004; Artavanis-Tsakonas et al., 2006). TIR-like proteins are essential for interaction in the TLR signal transduction pathway. One of at least two genes encoding a cytosolic protein with TIR-like domain (tir $A$ ) was found to participate in an immune-like response in Dictyostelium (Chen et al., 2007). A special type of cells, the S (,sentinel”) cells, carry out detoxification and immune-like phagocytosis. They thus provide a simple innate immune system for the social amoebae, being functional analogues of neutrophils and macrophages. The tirA protein performs a role of immune-related sig- 
nalling system in the response of Dictyostelium to bacteria. This suggests that the use of TIR domain-based signalling for defense is an ancient function already present in the progenitor of all present-day groups of eukaryotes, preceding the appearance of multicellularity.

The choanoflagellates, unicellular and colonial protozoans closely related to sponges (King et al., 2003), have a number of cell-signalling and adhesion protein families typical for the metazoans; these include cadherins, C-type lectins, several tyrosine kinases, and components of tyrosine kinase signalling pathways. The presence of proteins involved in cell to cell interaction in protozoans demonstrates that these proteins evolved before the origin of multicellular animals and were later co-opted for their development.

\section{CELLS OF THE IMMUNE SYSTEM}

It seems self-evident that the necessity for protection of integrity of organisms against parasites intensified dramatically with the appearence of multicellular organization and brought about further improvements of immunity. The evolutionary ,arms race” resulted in sophistication of both immune reactions and ways to "cheat" the host's immune system by parasites. It is a popular, but wrong, assumption that highly specialized blood cell types involved in gas transport (erythrocytes), blood clotting (thrombocytes) and immune response/tissue repair (leukocytes) are specific to the vertebrates. Actually, freely moving cells that have properties of at least some of the vertebrate blood cells are present in all animals (Hartenstein, 2006). In animals without the coelom (epithelium-lined body cavity) these cells are named amoebocytes, interstitial cells or neoblasts. In animals that have evolved the coelom along with a vascular system, these cells are commonly referred to as coelomocytes and/or haemocytes.

Sponges represent presumably the most basal clade of multicellular animals (Metazoa). The gelatinous matrix (mesoglea) between the ectoderm and endoderm of their body contains large numbers of motile amoebocytes that carry out multiple functions, the most primitive being digestion. Cnidarians and ctenophores also have a cell-rich mesoglea with interstitial cells that may act as phagocytes (Fautin \& Mariscal, 1991). Haemocytes occur in the vascular lumen and the coelomic cavity (coelomocytes) of all coelomate invertebrates. Plasmatocytes, one of four classes of haemocytes, can be compared to monocytes/macrophages/ histiocytes of vertebrates. These are phagocytic cells involved in the removal of apoptotic cells during the development, as well as in the ingestion or encapsulation of pathogens (innate immune response). Granulocytes (the second of the four classes of haemocytes) are involved in developmental and metabolic functions, as well as in immune functions including wound healing, blood clotting, phagocytosis and encapsulation of pathogens. In Drosophila, injuries evoke a clotting response that consists of the aggregation of haemocytes, followed by plasma coagulation caused by release of clotting factors from storage granules in haemocytes. Foreign bodies (such as eggs of parasites deposited in the host body cavity) are countered by cellular capsules formed by the plasmatocytes. Phenol oxidase is involved in the clotting as well as encapsulation of pathogens. In invertebrate deuterostomes (echinoderms, hemichordates, cephalochordates, and urochordates), haemocyte classes with characteristics similar to those in other invertebrates occur. Granular haemocytes and macrophages have been described in the coelom and vascular lumen of Amphioxus (Rhodes et al., 1982). Haematopoiesis in insects is under the control of a number of transcription factors and signalling pathways (such as GATA factors, JAK/STAT or Notch pathways) (Meister \& Lagueux, 2003), most of which have homologues that participate in the control of mammalian haematopoiesis.

\section{MOLECULES USED IN SPONGE IMMUNITY}

The Porifera include the least derived of metazoans, lacking epithelial (except for some species of controversial affinities) or muscular tissues. Despite their anatomical simplicity, sponges have molecules similar in structure to those involved in the immune system in higher animals. This concerns both the self/non-self recognition and the innate immune system in mammals based on phagocytosis, the complement system, and macrophage-derived cytokines.

\section{Self/non-self recognition}

Sponges, like other animals including mammals, demonstrate immunological self-tolerance (Moscona, 1968). A strong up-regulation of integrin receptors at zones between sponge autografts suggests their functional involvement (Wimmer et al., 1999). It has also been found that sphericalshaped Suberites cell aggregates of different species cultivated in vitro initiate a signal transduction mechanism resulting in the induction of a gene encoding preB-cell colony-enhancing factor $(\mathrm{CEF})$. The identity between the human and sponge genes is over 55\% (Samal et al., 1994). The human preB-cell CEF is a secreted protein and its gene can be induced in lymphocytes by a lectin, however, it is not tissue specific. A cytokine-responsive macrophage molecule termed allograft inflammatory factor 1 (AIF-1) has been identified in rat cardiac allografts (Utans et al., 1995). The expression of the sponge gene encoding a putative AIF-1 protein was observed both in autografts and allografts from Suberites (Müller et al., 1999). Like the vertebrate molecules, also the sponge AIF-1-related protein has an EF-hand $\left(\mathrm{Ca}^{2+}\right.$-binding) motif and a motif characteristic of peptide hormones. All this strongly suggests that sponges are provided with a molecular mechanism to recognize non-self. Some components of this mechanism, e.g., proteasome genes (Pancer et al., 1996b), have already been found. It was previously assumed (Humphreys et al., 1994) that in invertebrates the process of allorecognition is based primarily on active recognition of "self," but it appears that, similarly as in vertebrates, allorecognition in sponges involves also reactions to "non-self" antigens. It has been suggested that during allorecognition tissue responses the melanization occurs as well (ref. in Müller et al., 1999b). Melanin is a polymer formed by phenoloxidase(s) from tyrosine, which is produced from phenylalanine by phenylalanine hydroxylase $(\mathrm{PAH})$. In the sponge Geodia, allogeneic rejection involves an up-regulation of PAH. The sponge enzyme is the phylogenetically oldest member of a group to which all metazoan PAHs belong (Wiens et al., 1998).

\section{Phagocytosis}

In mammals, macrophages are the firs'T-cells that encounter non-self material, especially bacteria, and engulf 
and subsequently degrade them using hydrolytic enzymes and oxidative attack. A variety of receptors on macrophages are used to detect infection. Recognition of bacteria and apoptic hosT-cells by scavenger receptors induces phagocytosis or endocytosis (Kindt et al., 2007). Phagocytosis is the major cellular defense system in sponges. Phagocytized bacteria on which sponges feed are ingested with the help of both oxidative (Peskin et al., 1998) and nonoxidative (enzymatic) mechanisms. Several cDNAs coding for lysosomal enzymes, e.g., cathepsin (Krasko et al., 1997) have been isolated from sponges. Type I macrophage scavenger receptor has highly conserved cysteine-rich (SRCR) domains (Resnick et al., 1994). The SRCR domain consists of approx. 100 amino acids with conserved spacings of six (group A) to eight (group B) cysteines which form intradomain disulfide bonds. Both types of SRCR domains are found in a putative sponge aggregation receptor, AR (Pancer et al., 1997; Blumbach et al., 1998) and a putative sponge "multi-adhesive protein". The SRCR domains are found in receptors of higher metazoans, for instance in speract (sperm-activating) peptide receptor of see urchin egg (Dangott et al., 1989), human CD6 antigen (group B scavenger receptor), macrophage M130 antigen, as well as in soluble protein complement factor I. The putative sponge "multi-adhesive protein" comprises, besides the SRCR module, a fibronectin module, and a short consensus repeats (SCR) module. This latter module is present in the putative aggregation receptor as well (Blumbach et al., 1998). The short consensus repeats are typical for the mammalian complement control (regulatory) protein superfamily (Reid \& Day, 1989) and coagulation factor XIII-b (Nonaka et al., 1993). The sponge SCR repeats region (370 amino-acids) reveals a similarity to mammalian selectins, mammalian complement receptors, and invertebrate SCR proteins (Limulus clotting factor C), all of which are characterized by four conserved cysteine residues in each repeat.

\section{Sensing of pathogens}

Sponges possess recognition systems for pathogenic bacteria and fungi. The lipopolysaccharide (LPS)-interacting protein on the sponge cell surface is a receptor for Gram-negative bacteria. Upon binding to LPS (endotoxin), the receptor dimerizes and interacts with MyD88-like protein. A perforin-like molecule (with high sequence similarity to the mollusc macrophage-expressed protein) is up-regulated as result of LPS binding (Wiens et al., 2005). Additionally, Suberites responds to LPS with up-regulation of tachylectin, a D-GlcNAcbinding lectin (Schröder et al., 2003). In higher metazoans, LPS-interacting proteins bind the endotoxin in concert with TLRs. This association leads to a signal transduction cascade, resulting in an increased expression of genes coding for cytokines (e.g., interferon or tumor necrosis factor) (Pålsson-McDermott \& O'Neill, 2004; Wiens et al., 2007). In the sponge immune response to bacterial lipopeptides, three major elements, TLR, the IL-1 receptor associated kinase-4 like protein (IRAK-4l), and a novel effector caspase from Suberites, have been identified. Suberites recognizes Gram-positive bacteria through binding to the bacterial proteoglycan (ref. in Wiens et al., 2005); consecutively, the sponge cells respond with increased synthesis of lysozyme and endocytic activity. With respect to fungi, sponges are provided with a cell surface receptor recognizing $\beta(1 \rightarrow 3)$-D-glucans (Perović-Ottstadt et al., 2004); after binding, a signal transduction pathway is initiated that results in the expression of genes encoding a fibrinogen-like protein and epidermal growth factor. These anatomically least derived extant metazoans already possess the signaling pathways typical for the antimicrobial immune systems of other metazoans. Like in mammals, after LPS binding to sponge cells (ref. in Wiens et al., 2005) the mitogen-activated protein kinase pathway is activated (p38 kinase and c-Jun N-terminal kinase) (ref. in Wiens et al., 2005; Böhm et al., 2000) and the NF- $x \mathrm{~B}$ pathway (Wiens et al., 2005; 2007) are activated. The $N F-x B$ gene of the sponge Amphimedon queenslandica has been found to be expressed during $A$. queenslandica embryogenesis, suggesting a developmental role, but it is possible that $N F-x B$ also has an immune function in sponges (Gauthier \& Degnan, 2008).

Molecules involved in signal transduction in sponges show sequence similarity to molecules found in higher metazoan phyla. The LPS-interacting protein is related to the aggregation factor known from the sponges $M i$ crociona (Fernàndez-Busquets \& Burger, 1997) and Geodia (Müller et al., 1999a). The LPS-interacting protein has, for instance, a threonine/proline-rich motif that is also found in other metazoan receptors (Gan et al., 2004). Perforin-like molecules are involved in defense against bacteria in humans (Ambach et al., 2004) and molluscs (Mangel et al., 1992), as well as in the sponge system (Wiens et al., 2005). The sponge perforins show considerable sequence similarity to the mammalian macrophage-expressed protein, as well as the mollusc Haliotis protein (abMpeg1); it is especially high within the perforin domain (Mah et al., 2004). Since the sponge MyD88 (in higher metazoans, MyD88 is an adapter protein for TLR) has a TIR domain but lacks a clear death domain, and the predicted extracellular domain of the sponge TLR lacks true leucine-reach repeats (LRRs) the presence of canonical Toll/TLR pathway in sponges is, according to Hemmrich et al. (2007), not evident.

\section{Molecules of vertebrate adaptive immune system (AIS)}

Some precursors of the adaptive immune system of mammals have also been traced in sponges. The expression of a protein similar to mammalian lymphocyte-derived cytokine is up-regulated during non-self-recognition in Suberites. In Geodia, two classes of receptors with Iglike domains have been identified: receptor tyrosine kinase (RTK) and the non-enzymic sponge adhesion molecules SAM. They contain two polymorphic Ig-like domains. The expression of these molecules is also upregulated during grafting. Amino acid substitutions within the Ig-like domains in Geodia are restricted to ,hot spots" (Pancer et al., 1996a). The Geodia RTK molecule comprises (1) an extracellular part with a Pro/Ser/Thr $(\mathrm{P} / \mathrm{S} / \mathrm{T})$-rich region and two complete immunoglobulin (Ig)-like domains, (2) a transmembrane domain, (3) a juxtamembrane region, and (4) a catalytic tyrosine kinase (TK) domain (ref. in Müller et al., 1999a). The intraspecies polymorphism of Ig-like domains suggests that RTK is probably a key molecule involved in recognition in Geodia (Pancer et al., 1998). Two sponge adhesion molecules (SAM) have been isolated, differing in size (Blumbach et al., 1999). The Ig-like domains are present in both species. Only the long form of SAM contains a Pro-Ser-Thr-rich domain. It may be noted that the Tcell receptor has a structure similar to that of the sponge adhesion molecules from Geodia: two extracellular Ig- 
like domains and a short cytoplasmic tail (Müller et al., 1999a). To conclude, it seems that at the moment of splitting off of the evolutionary branch of sponges many of the key molecules that are used in higher vertebrates for their innate and adaptive immune systems were already developed. It is likely that some of those molecules acquired a dual function during subsequent evolution, first as cell adhesion receptors or growth control factors and then as immune molecules required for self/ non-self-recognition. At present however, it cannot be stated with certainty whether the sponge proteins showing high sequence similarities with the immune proteins of other lower invertebrates or mammals also have similar function.

\section{RECEPTORS IN INNATE IMMUNITY}

Various kinds of pattern recognition receptors (PRR) are involved in the identification of foreign factors in vertebrates and invertebrates (Akira et al., 2006). They seem to have originated independently of each other by recruiting molecules or pathways earlier performing different physiological or developmental functions in ancestral organisms. Among such receptors of different evolutionary origins are scavenger receptors and Toll-like receptors. Also cytokine-like receptors and lectins may have originated in invertebrates independently from their vertebrate counterparts and may be unique to a particular taxonomic group.

\section{Scavenger receptors}

Scavenger receptors have high affinity for a broad array of polyanionic ligands (bacteria, modified lipopolyprotein, for instance acetylated low-density lipopolyprotein, and apoptotic cell debris). The ability to bind polyanions appears to be a widely conserved feature and, as a consequence, various classes $(\mathrm{A}-\mathrm{H})$ of scavenger receptors have little structural and weak functional homology (reviewed in Peiser et al., 2002). The scavenger receptor cysteine-rich domain (SRCR) is an ancient and highly conserved protein module of about 100 amino acids. In sponges that do not have specialized immune cells, the scavenger receptors appear to be fairly evenly distributed in the sponge body. They may have various roles, such as adhesion and aggregation mediated through cell-cell interactions (Blumbach et al., 1998; Pahler et al., 1998), owing to the presence of the fibronectin domain. The sea urchin genome contains approx. 150 genes encoding proteins with of one or more SRCR domains; however, the functions of these genes are not clear. Many of these 150 proteins containing SRCR domains have multiple splice variants (Pancer, 2000). Unequivocal class C scavenger receptors have been found up to date in Drosophila (Lazzaro, 2005), amphioxus (Huang et al., 2008), and lamprey (Mayer \& Tichy, 1995). This lamprey scavenger receptor may be involved in intercellular contacts and cell activation or differentiation in the immune system as it is a type-I integral membrane glycoprotein containing two SRCR domains flanking five epidermal growth factor (EGF)-like repeats. In the teleost fishes, scavenger receptors have been found to be expressed on subsets of non-specific cytotoxic cells (equivalent to natural killer cells) (Kaur et al., 2003) and on phagocytic cells. Whether the SRCR domain originated from a single ancestral gene early in the evolutionary history or arose several times independently is not clear. Although it appears to be present in the genome of both lower metazoans, such as sponges, and higher ones, such as mammals, there are organisms (for example nematodes) in between that do not have proteins containing SRCR domains.

\section{Toll-like receptors}

Toll-like receptors (TLRs) are type I integral membrane glycoproteins possessing extracellular domains with varying numbers of leucine-rich repeats (LRR) motifs, and a cytoplasmic signalling domain homologous to that of interleukin 1 receptor (IL-1R). This domain, TIR, which denotes Toll, interleukin-1 receptor, and plant disease resistance genes (Beutler \& Rehli, 2002) is the most conserved protein motif within the Toll-like receptors. A TIR-like domain was suggested to be present in prokaryotes (Beutler \& Rehli, 2002) and has been found in amoebae (Sillo et al., 2008). In plants, the $\mathrm{N}$ gene of tobacco is related in sequence to Toll and many additional plant disease resistance genes encode Pelle homologues such as Pto (Whitham et al., 1994; Tang et al., 1999). Pelle is a homologue of mammalian IL-1R-associated kinases (IRAKs). The plant LRR-TIR and Pelle-like R proteins most likely function in signalling cascades quite divergent from their Drosophila and human counterparts, as no plant Rel homologues (transcription factors) have been identified. This suggest that Pto could participate directly in pathogen recognition (Rathjen et al., 1999; Tang et al., 1999).

The Toll/TLR pathway in animals predates the cnidarian-bilatelarian divergence. The canonical Toll/TLR pathway is present in the anthozoan cnidarians (Miller et al., 2007). A Toll/TLR protein closely resembling Drosophila Toll in both domain structure and amino-acid sequence is found in these animals (Hemmrich et al., 2007). Toll like receptors are confined to the metazoan phyla occurring in most of them, except for flatworms and annelids (Kanzok et al., 2004). Based on molecular phylogenetic interpretations, these groups of animals are closely related as members of the spiralian (Lophotrochozoa) clade, the flatworms (Platyhelminthes) being located at the tip of the tree, above the Annelida and Mollusca. One secondary loss of TLR is thus enough to explain this pattern of occurrence (but TLR are known in bivalve mollusks). The two nematode TLRs (from Caenorhabditis and Strongyloides) form a separate cluster basal to all those of arthropods (both phyla belong to the Ecdysozoa clade) but are distinct from the vertebrate ones. Tol-1 (the only Tlr gene) expression in adults Caenorhabditis is restricted to the nervous system and is implicated in embryonic development and pathogen recognition. Tol-1 Caenorbabditis mutants are susceptible to bacterial infection (Akira et al., 2006) and it was shown that the Toll gene is involved in chemosensory perception of pathogenic bacteria, thus contributing indirectly to the host defense (Pujol et al., 2001). Results of Tenor and Aballay (2008) indicate that Tol-1 has a direct role in response to certain Gram-negative bacteria and is required for the correct expression of $\mathrm{ABF}-2$, which is a defensin-like molecule, and heat-shock protein 16.41, which belongs to the HSP family of proteins required for $C$. elegans immunity. These results show that a part of the TLR-mediated immunity is evolutionarily conserved. However, the role of Tol-1 in C. elegans immunity is not central and another candidate for the immune receptor has been proposed from LRR-containing receptors (Irazoqui et al., 2010).

Drosophila Toll1, the most important member of its family, cannot be considered a homologue of mammalian TLRs. In contrast to mammalian TLRs, expression 
of Drosophila Tolls is not restricted to immune-responsive cells. Rather, Tolls show complex stage- and tissue-specific expression patterns during embryonic and larval development. Almost all arthropod TLRs (with the exception of Toll9 which cluster with mammalian TLRs) form a separate cluster from the mammalian counterparts although they share a common ancestor (Luo \& Zheng, 2000). This leads to the suggestion that TLR-mediated immunity developed independently in arthropods and mammals. In both pathways (immune and developmental) of insect the Toll protein first binds the extracellular protein Spätzle (a protein with structural similarities to mammalian neutrophins). The generation of distinct Spätzle fragments by two distinct proteolytic cascades is thought to orientate the Toll pathway towards developmental or immune regulation (Beschin et al., 2001). A bivalve TLR was found to be homologous to Drosophila Tolls; moreover, expression of this receptor was regulated by LPS (Qiu et al., 2007). In the horseshoe crab tToll does not function as an LPS receptor on granular haemocytes. It seems possible that the clotting protein coagulin may induce dimerization or oligomerization of tToll, leading to the activation of intercellular signalling (Inamori et al., 2004). Some animal species appear to have many more TLRs than others. For instance, in a see urchin 222 genes encoding Toll-like receptors were found (Rast et al., 2006). The Amphioxus genome contains 71 TLR genes (Huang et al., 2008). Mammalian Toll-like receptors (12 members) are grouped into six families on the basis of sequence similarities. All these families are conserved in vertebrates from fish to mammals (Akira et al., 2006).

According to the predominant view, a signalling pathway has been coopted from the developmental role for innate immunity function (Akira et al., 2006). In view of the presence of a canonical Toll/TLR pathway in cnidarian immunity, the opposite view should be considered as well. Although TLR-mediated immunity developed independently in arthropods and mammals, Toll signaling is highly evolutionarily conservative, as similarities between proteins taking part in mammalian and Drosophila signal pathways are obvious. In Drosophila, infection with fungi or Gram-positive bacteria activates the Toll pathway similarly to the mammalian Toll pathway. In mammals, however, TLRs interact with microbial pattern molecules, whereas in the fruitfly the invading Gram-positive bacteria are recognized by peptidoglycan-recognition proteins, followed by the activation of the Toll ligand Spätzle via a protease cascade. Spätzle binds Toll, initiates signaling pathways by recruiting Drosophila MyD88 and Pelle (which has a serine-threonine kinase domain and is homologous to mammalian IRAKs) and induces nuclear translocation of the NF- $x$ B-related transcription factors Dorsal and DIF. The end effect of Toll signalling is the dissociation of transcription factors from the protein Cactus, a homologue of mammalian I $x$ Bs (Hoffmann, 2003). In Drosophila, Gram-negative bacteria activate the IMD pathway. The putative receptor, Peptidoglycan recognition protein (PGRP)-LC, containing a transmembrane domain is responsible for the activation (Gottar et al., 2002). The IMD protein contains a death domain highly homologous to that of mammalian RIP (TNFreceptor-interacting protein) (Hoffmann, 2003). Drosophila homologues of mammalian FADD (which associates with IMD), TAK1 (TGF- $\beta$ activated kinase 1) and IKK- $\beta$ (an equivalent of mammalian signalosome) induce phosphorylation of a NF- $x$ B-like protein (Relish), which results in its cleavage and subsequent nuclear translocation. Relish induces the expression of genes encoding antimicrobial peptides against Gramnegative bacteria. It is worth to note that the nematode $C$. elegans, unlike other animals, has genes of the Pelle, IxB, and TRAF families (Tan \& Ausubel, 2000) besides Tlr, a single gene of each. C. elegans lacks NF$x B$ and $M y D 88$. NF- $x \mathrm{~B}$ and MyD88 are part of Toll signalling in the inflammatory response (Irazoqui et al., 2010). These genes have apparently been lost by the nematodes, as they are present in the cnidarian genome (Miller et al., 2007).

\section{Lamprey lymphocyte-like receptors}

Lymphocyte-like cells of the agnathan see lamprey Petromyzon have variable lymphocyte receptors (VLR) with leucine-rich repeat (LRR) segments (known from extracellular domains of TLR) as counterparts of the immunoglobulin-based receptors that jawed vertebrates use for antigen recognition (Pancer et al., 2004a). The highly diverse VLR genes are somatically assembled by the insertion of variable LRR sequences into incomplete germline variable lymphocyte receptor genes. Each germline receptor gene is flanked by hundreds of LRR-encoding sequences, and these are randomly used as templates to add the missing receptor segments needed for completion of the mature gene (Alder et al., 2005). Variable lymphocyte receptors are expressed by separate monoallelic lymphocyte populations $\mathrm{A}$ and $\mathrm{B}$, ensuring that each lymphocyte expresses a receptor of unique sequence (Guo et al., 2009). The presence of LRR in receptors on A-like and B-like lymphocytes in lampreys suggests a way of the evolution of adaptive immunity different than in other vertebrates. Similarities with the antigen recognition system of jawed vertebrates are evident, as only VLRB lymphocytes bind native antigens and differentiate into VLR antibody-secreting cells. Conversely, VLRA lymphocytes respond preferentially to a classical T-cell mitogen and up-regulate the expression of the pro-inflammatory cytokine genes interleukin-17 (IL-17) and macrophage migration inhibitory factor (MIF).

\section{INVERTEBRATE IMMUNE RESPONSES}

The invertebrate innate immune responses include both cellular and humoral components. The cellular responses are mediated by haemocytes (blood cells) which typically phagocytose microbial pathogens and form melanotic capsules around metazoan parasites (Nappi \& Ottaviani, 2000). Humoral immunity includes activation of proteolytic cascades that initiate haemolymph clotting, synthesis of lysozyme and various antimicrobial peptides, generation of reactive oxygen and nitrogen species, and synthesis of proteolytic enzymes (Nappi \& Ottaviani, 2000). Several studies have demonstrated striking parallels between the innate immune responses of insects and other invertebrates on one hand and mammals on the other hand. These parallels indicate that the innate systems of vertebrates and invertebrates have common ancestry (Ottaviani \& Franceschi, 1997)

Recognition of a foreign object or pathogen leads to its elimination. This is performed by cells with natural killer-like activity found in many invertebrate organisms: crayfish, snails, earthworms, urochordates, and molluscs (Cooper et al., 1996). In earthworm coelomocytes, a protein similar to perforins, very ancient self-assembling 
proteins, has NK-like activity. The sequence analysis of this protein shows that it contains a cysteine-rich domain like mouse perforin and lytic complement component C9 (Kauschke et al., 2001).

\section{Clotting}

In invertebrates, haemolymph coagulation (Muta \& Iwanga, 1996) and melanin formation are responses to microbial surface antigens (Söderhäll et al., 1994). Two types of clotting mechanisms are known there. One of these is found in crustaceans (lobster and crayfish) and insects (cockroach and grasshopper) (ref. in Muta \& Iwanga, 1996) where the gel is formed through polymerization of clottable protein(s) catalyzed by a $\mathrm{Ca}^{2+}$-dependent transglutaminase. The transglutaminase is released from the haemocytes or muscle cells through an unknown mechanism. It is worth to note that in mammals, homopolymers of fibrin are stabilized by intermoleculary cross-links made by plasma transglutaminase (Osaki \& Kawabata, 2004). The clottable proteins isolated from crustacean haemolymph plasma are large dimeric lipoglycoproteins consisting of subunits of about $200 \mathrm{kDa}$ (Fuller \& Doolittle, 1971; Kopacek et al., 1993). Their amino-terminal sequences suggest that these are vitellogenin-like proteins (Doolittle \& Riley, 1990). Vitellogenin is the major yolk protein found in most egg-laying non-mammalian vertebrates and inveterbrates (Smolenaars et al., 2007). In insects, another abundant plasma protein, lipophorin (the major lipid carrier protein in insects) (Ryan \& Van der Horst, 2000) seems to be cross-linked upon gelation (Brehelin, 1979; Barwig, 1985). In the moth Manduca, an inducible glucose-specific lectin possesses haemocytecoagulating activity (Minnick et al., 1986).

In the marine chelicerate horseshoe crab Limulus, coagulation involves haemocyte serine protease zymogens that trigger a coagulation cascade in response to LPS and $\beta$-1,3-glucan (Muta \& Iwanga, 1996). The haemocyte detects LPS molecules on their surface, and then releases to the haemolymph the contents of its granules. Among granular components, coagulation factor zymogens have been found. In the presence of LPS, the autocatalytic activation of factor $C$ triggers the coagulation cascades (factor B, clotting enzyme) resulting in the conversion of coagulogen to an insoluble coagulin gel. The factor $G$ zymogen is activated in the presence of $\beta(1 \rightarrow 3)$-D-glucan (Muta et al., 1995). The resulting active factor $G$ activates the proclotting enzyme directly, which brings about coagulin gel formation. This $\beta$-glucan-mediated coagulation pathway is activated on the surface of fungi. As a result of the clotting cascade, the invaders into the haemolymph are engulfed or immobilized by the clot. The coagulation cascade is regulated with the help of three types of serpin-type serine protease inhibitors exocytosed upon activation of the haemocytes to prevent diffusion of active coagulation factors, which could cause unnecessary clot formation. Several components of this cascade have been found to contain various protein domains. One of three chains of factor $\mathrm{C}$, chain $\mathrm{H}$ that binds LPS, contains five SCR also called CCP domains, an EGF-like domain, and a C-type lectin-like domain (Muta et al., 1991). The SCR domains are found mainly in mammalian complement factors. The amino-terminal L chains of factor B and the proclotting enzyme contain a small compact domain with three disulfide bonds called "clip" domain (disulfide-knotted domain) (ref. in Muta \& Iwanga, 1996). The „clip” domain has been found in the Drosophila Snake and Easter protease precursors (Smith \& DeLotto, 1992). These clotting mechanisms are homologous to similar mechanisms known in vertebrates.

\section{Melanization}

Biosynthesis of melanins occurs in a wide range of organisms, from bacteria and protozoans to mammals, indicating high evolutionary conservation and also fundamental importance of melanogenesis, even though its primary function is still obscure (Płonka \& Grabacka, 2006). It may be argued that melanization of an infected tissue is either just a side-effect of the protection against the ongoing inflammatory processes or an active defense against the pathogen (Marmaras et al., 1996). No doubt melanin protects from UV light and ionization, and supports resistance to heat or cold (Nosanchuk \& Casadevall, 2003; Płonka \& Grabacka, 2006). In arthropods, melanization is associated with multiple host defense mechanisms leading to the sequestration and killing of invading microorganisms as well as with the sclerotization of the new postmolt exoskeleton (Terwilliger \& Ryan, 2006). The arthropod melanization is controlled by a cascade of serine proteases (not yet characterized) that ultimately activates the enzyme phenol oxidase which, in turn, catalyzes the synthesis of melanin (Cerenius \& Söderhäll, 2004). The prophenoloxidase-activating enzymes cloned from insects are homologous to the horseshoe crab clotting enzyme and Factor B (ref. in Nagai \& Kawabata, 2000). These two host defense systems of haemolymph clotting and prophenol oxidase activation have evolved from a common ancestral protease cascade (Nagai \& Kawabata, 2000).

The melanin pathway results in the formation of cytotoxic pigment precursors (quinones, quinone methides, and semiquinones) as well as ROS and RNS (Nappi \& Ottaviani, 2000). Insect phenol oxidase shows a close phylogenetic relationship with the arthropod haemocyanins, the copper-binding proteins involved in oxygen transport (Decker et al., 2007). Haemocyanin can function as a phenoloxidase under certain conditions (Terwilliger \& Ryan, 2006). In the mosquito Armigeres phenol oxidase is transcriptionally upregulated during the melanization of parasitic microfilariae, and is synthesized only in the mosquito haemocytes (Cho et al., 1998). In Drosophila, phenol oxidase activity in immune reactive larvae was markedly augmented during the early stages of melanotic encapsulation of eggs of the parasitic wasp Leptopilina. The recruitment and site-specific aggregation and adhesion of large numbers of haemocytes that form melanized capsules around eggs of Leptopilina coincides with an augmented production of reactive oxygen and nitrogen species (Nappi et al., 1995), which appear to represent an evolutionarily conserved innate immune response.

\section{Reactive oxygen and nitrogen species}

Reactive oxygen and nitrogen species are produced by members of all metazoan phyla. Sponges produce superoxide during consumption of bacteria, so it can be viewed as an antibacterial agent (Peskin et al., 1998). Mollusc haemocytes produce superoxide in response to specific stimulators of respiratory burst (Garcia-Garcia et al., 2008). Production of reactive oxygen species by haemocytes has been found in the cattle tick Boophilus (Pereira et al., 2001). An immune response resembling the respiratory burst was found in the haemolymph and haemocytes of the cockroach Blaberus (Whitten et al., 1999). The source of the reactive oxygen species could be the process of melanization or activity of NADPH oxidase, a key enzyme of the innate defense found in phagocytes of mammals (Dzik et al., 2006; 2010). 
The reactive oxygen-generating NADPH oxidases (Noxes) function in a variety of biological roles, besides host defense, e.g., in signal transduction and hormone synthesis. Genes encoding a family of these enzymes are found in a variety of eukaryotes, including plants, but there is no evidence for the presence of NADPH oxidases in prokaryotes (Sumimoto, 2008). Nox enzymes reduce molecular oxygen to superoxide in conjunction with oxidation of NADPH. The superoxide is further converted to various reactive oxygen species (Dzik, 2006). The prototypic Nox, gp91phox/ Nox2 is a membrane-associated catalytic subunit of the phagocyte NADPH oxidase with a bis-heme binding motif. This suggests a possible evolutionary and functional relationship with the prokaryotic (or organellar) $b$ type cytochromes. The oxidase C-terminal cytoplasmic region is homologous to the prokaryotic and organellar enzyme ferredoxin reductase (Sumimoto, 2008 and references therein). In animals, the phagocyte oxidase gp91phox/Nox2 was present before the divergence of Choanoflagellata and the metazoans. Thus, it is likely that Nox 2 is the most ancient Nox in animals. During the evolution of protostomes, Nox2 was lost in the exuviating animals (Ecdysozoa), as it is missing in both arthropods (Drosophila) and nematodes (Caenorhabditis) but present in all other metazoan phyla. Thus, the ROS produced by arthropod hematocytes must originate from an enzyme other than Nox2 (Ha et al., 2009). The phagocytic NADPH oxidase of mammals is a multicomponent complex comprising proteins of different subcellular location, both membrane-bound (p22phox and gp91phox forming the flavocytochrome $\left.b_{558}\right)$ and cytosolic (p40phox, p47phox, p67phox), and a small GTP-binding protein Rac. Upon cell activation, the cytosolic subunits are phosphorylated and migrate to the membranes where they bind to the membrane subunits to assemble the active oxidase (Babior, 1999). The gene encoding p22phox is present in the Choanoflagellata, Cnidaria, and Mollusca, but is absent from Annelida and Echinodermata as well as Ecdysozoa, the latter observation consistent with the absence of the Nox1-4 subfamily in this group. It is interesting that the three residues (Pro152, Pro156 and Arg158) in human p22phox indispensable for binding to p47phox are invariant in all animal p22phox proteins (Sumimoto, 2008), although an identifiable p47phox subunit is only found in chordates. The acrasiid "amoeba" Dictyostelium has a protein similar to p67phox, but none homologous to 447 phox, p40phox or p22phox (Lardy et al., 2005). This protein contains a Rac-binding tetratricopeptide repeat (TPR) domain, but does not contain any identifiable activation domain. The domain architecture of p47phox and p67phox is conserved from fishes to mammals. The genome of the chordate $A m$ phioxus contains both genes (in p47phox the whole domain structure is duplicated). This indicates that this gene emerged early in chordate evolution. On the other hand, p67phox seems to be absent in the urochordates suggesting its loss in this lineage. A urochordate protein that contains solely the Rac-binding TPR domain, but not the other domains of p67phox, is interpreted as a functional p67phox homologue (Inoue et al., 2005). The p67phox-homologous proteins known from molluscs (Kawahara \& Lambeth, 2007) and echinoderms (Genebank accession number XP 781982) may participate in oxidase activation without cooperating with p47phox (which is absent there). The gene encoding p40phox occurs only in chordates (Sumimoto, 2008).
Nitric oxide synthase (NOS) activity has been detected in almost all organisms (ref. in Palumbo, 2005). The primary function of nitric oxide is signalling role through activation of guanylate cyclase and cGMP formation. In sponges, $\mathrm{NO}$ is a cellular signal for environmental stress (Giovine et al., 2001), which may represent the most primitive NO-based sensory network in the animal kingdom. In invertebrates, NO is a messenger in a variety of tissues, including the nervous system, excretion organs (ink gland, salivary gland), light organs, haemocytes, and endocrine cells. In the ink gland cells of the cephalopod Sepia, NO signalling activates tyrosinase leading to the melanin formation responsible for the black color of its ink. The NO/cGMP signalling pathway is also involved in secretion of ink constituents from gland cells. In insects, NOS expression is associated with neuronal signalling (Elphick et al., 1996) and production of NO-loaded salivary gland proteins that facilitate blood-feeding by haematophagous insects (Ribeiro et al., 1993). In Drosophila NO induces expression of a gene encoding the antimicrobial peptide diptericin (Nappi et al., 2000). A defense function of nitric oxide molecule was observed in crustacean (Yeh et al., 2006) and mollusc haemocytes (ref. in Palumbo, 2005). In haemocytes of the mollusc Mytilus, free radical production has been found to depend mainly on the activity of PI 3-kinase (Garcia-Garcia et al., 2008). In mammals, nitric oxide is a major messenger molecule involved in vascular regulation, immune function and neurotransmission in the brain and peripheral nervous system.

No wonder that nitric oxide synthase shows high similarity across the Metazoa. The enzymes cloned from the cnidarian Discosoma, mollusc Aplysia, and chordate Ciona have putative cofactor recognition sites for haeme, tetrahydrobiopterin, calmodulin, FMN, FAD, and NADPH; all conserved with respect to mammalian NOS (ref. in Palumbo, 2005). The nitric oxide synthase gene of the mosquito Anopheles shows the highest homology to the vertebrate neuronal NOS (Luckhart \& Rosenberg, 1999). Phylogenetic analysis shows that in the sea urchin Arbacia, each of two cloned sequences of NOSs cluster with the mammalian constitutive and inducible isoforms, respectively (Cox et al., 2001). They may represent early homologues of these two isoenzymes. The signals that trigger the inducible synthesis of nitric oxide in invertebrates are unknown (Rivero, 2006), although an LPSand inflammatory cytokine-responsive transcription binding site has been found (Luckhart \& Rosenberg, 1999).

\section{Antimicrobial peptides}

The killing of pathogens in invertebrates involves also oxygen-independent mechanisms that include the synthesis of lysozyme and other hydrolytic enzymes, and antimicrobial peptides. Antimicrobial peptides (about 900 are known) are produced by both protozoa and metazoa (Danilova, 2006). Although these peptides are quite different, they all contain clusters of hydrophobic and cationic amino acids conserved during evolution (Zasloff, 2002). They are essential for the attachment to the negatively charged bacterial membranes and integration with membrane phospholipids in pore-forming or membrane destruction (Brogden, 2005). The cytoplasmic granular vesicles of the parasitic Entamoeba contain a family of peptides (amoebapore A, B, and C) that display antibacterial activity primarily towards Gram-positive bacteria (Leippe et al., 1994). They resemble defensins of mammals and insects by the presence of three sta- 
bilizing disulfide bonds and pore formation in bacterial membranes, although they differ in positions of cysteins and secondary structure (ref. in Leippe, 1999). The 78-residue peptide named NK-lysin of porcine natural killer (NK) and T-cells is a structural and functional analog of the protozoan peptides (Leippe, 1995). Both amoebapores and NK-lysin occur in granules of their cells and are antibacterial as well as cytolytic, but do not lyse red blood cells. A human homologue of NKlysin termed granulysin was purified from cytotoxic $\mathrm{T}$ lymphocytes (Peña et al., 1997). Amoebapores, NK-lysin and granulysin belong to a distinct family of saposin-like proteins which includes saposins (cofactors of lysosomal sphingolipid hydrolases) and lung surfactant associated protein B (Munford et al., 1995). In phylogenetically distant organisms, the architecture of such lytic polypeptides may have developed independently under selection pressure for functionally important units (amphipathic $\alpha$-helices, stabilizing intramolecular crosslinks). Support for their common ancestry is provided by the cysteine pattern typical for amoebapores and other saposin-like proteins found in putative gene products of flatworms (Fasciola, Schistosoma), nematodes (Caenorbabditis), and arthropods (Bombyx) (Leippe, 1999).

Antimicrobial peptides are produced in the phagocytic cells of annelids (Salzet et al., 2006), molluscs, arthropods, and urochordates (ref. in Hancock et al., 2006). A great body of knowledge comes from investigation of insect antimicrobial peptides. They are synthesized primarily by the fat body (a functional equivalent of the mammalian liver) and to a lesser extent by haemocytes, cuticular cells, midgut and salivary glands, and reproductive structures. More than 150 antibacterial and antifungal peptides/polypeptides have been described. The immune peptides of insects may serve as cell adhesion molecules, in regulating the activity of cell surface receptors or signal transduction pathways leading to altered gene expression. Drosophila naturally infected by entomopathogenic fungi is able to differentially induce only those antimicrobial peptides with antifungal activities. In Drosophila and other insects a NF$x \mathrm{~B}$ homologue has been demonstrated to regulate gene transcription of antimicrobial peptides (Hoffmann et al., 1999). Following infection, the gene encoding the cytokine Spätzle was uniquely upregulated in haemocytes but not the fat body (Irving et al., 2005).

In animals, lysozymes constitute key components of the antibacterial defense due to the cationic nature of the protein and, to a lesser degree, its muramidase activity. These enzymes are known from numerous phylogenetically diverse organisms such as bacteria, bacteriophages, fungi, plants, and animals. The phylogeny of lysozymes shows conservation of their function since the last common ancestor of arthropods and vertebrates (Hughes, 1998). Cytoplasmic granules of Entamoeba contain two isoforms of lysozyme both of $23 \mathrm{kDa}$ (Leippe, 1999). Multiple lysozyme forms can be recognized in cases when it has also been recruited as a digestive enzyme (Prager, 1996). Amoeba lysozyme II having acidic $\mathrm{pI}$ is in this respect similar to one of eight isoforms from Drosophila. It is expressed exclusively in the digestive tract and hence is presumably a digestive enzyme (Daffre et al., 1994). Like in other phagocytes, amoebic lysozymes prevent microbial growth within the digestive vacuoles and, in addition, fulfill a digestive function to exploit bacteria for nutrition. A striking sequence identity of both amoeba lysozymes with putative gene products of unknown function from the bacteria-feeding nematode Caenorbabditis was found (Leippe, 1999).

\section{Lectins}

Lectins are proteins that recognize and bind carbohydrates. Intracellular lectins recognizing core-type structures and mediating intracellular glycoprotein trafficking are present in plants, yeasts, invertebrates, and vertebrates. Lectins that recognize more complex structures at the cell surface, such as C-type lectins and galectins, are found both in invertebrates and vertebrates, but their functions have evolved independently in different animal lineages (Dodd \& Drickamer, 2001). Lectins are present on the surface of invertebrate haemocytes as primitive recognition molecules. Their ability to opsonize and agglutinate foreign cells helps subsequent phagocytosis or encapsulation of microbial pathogens and metazoan parasites (Dodd \& Drickamer, 2001). An ancestral S-type lectin has been found in sponges (Pfeifer et al., 1993). A 32-kDa S-type lectin from the nematode Caenorhabditis shares 25-30\% sequence identity with the vertebrate members of that group (Hirabayashi, et al., 1992). Intermediate forms between S- and C-type lectins have been found in the venom of the rattle snake Crotalus (Hirabayashi et al., 1991). Convergent evolution seems responsible for the similarities in structure and/or function of some lectins (Vasta et al., 1994). Individual functional domains of these molecules are related to collagen, growth factors, calmodulin, and complement regulatory proteins. Common to all lectins are the carbohydrate-binding domains covering a set of highly conserved residues (Vasta et al., 1994). Although distinct and probably unrelated groups of proteins are included under the term "lectins" there are essential similarities between invertebrate and vertebrate lectins. One group of invertebrate lectins comprises molecules that show significant homology to membrane-integrated or soluble vertebrate $C$-type lectins. The second includes $\beta$-galactosyl-specific lectins homologous to the S-type vertebrate lectins. The third group are lectins that show homology to vertebrate pentraxins that exhibit lectin-like properties, such as C-reactive protein and serum amyloid. Moreover, there are lectins that do not exhibit similarities to any of the aforementioned categories. Although lectins do not express recombinatorial diversity, they have more than one binding site specific for different carbohydrates in a single molecule and also show certain flexibility of the binding sites allowing recognition of a range of structurally related carbohydrates (Vasta et al., 1994).

\section{Invertebrate cytokine-like molecules}

Functional analogues of mammalian inflammatory cytokines, for instance IL-1 and TNF-like molecules, have been found in annelids, molluscs, insects, echinoderms, and urochordates (ref. in Beschin et al., 2001). In fact, the functional similarities between cytokines and their invertebrate counterparts need not reflect homology but rather can result from molecular convergence based on the structural similarity of the lectin-like recognition domain. Various vertebrate cytokines possess lectin-like properties that may be involved in regulation of innate immune responses independent of the binding to their cytokine-specific receptor (Lucas et al., 1994; Zanetta \& Vergoten, 2003). The carbohydrate-binding domains of cytokines are spatially distinct from the cytokine-receptor binding sites. The action of urochordate IL-1-like molecule may be related to its galactosyl-specific lectin-like property rather than reflecting an evolutionary relation (Raftos, 1996; Beck et al., 1993). Coelomic cytolytic fac- 
tor (CCF) from the earthworm Eisenia triggers activation of the prophenoloxidase (proPo) cascade (involved in biosynthesis of melanin) upon interaction with cell wall components of Gram-negative bacteria or yeast. Despite the functional analogies between CCF and TNF (lytic abilities, lectin-like activities, secretion from coelomocytes or macrophages, respectively, after LPS stimulation) they are not homologous (Beschin et al., 1999).

The TGF- $\beta$ superfamily is a group of multifunctional cytokines that includes bone morphogenetic proteins (BMPs), TGF- $\beta$ s and others. The BMP subfamily members have a critical role in embryogenic patterning and in maintaining tissue homeostasis in adult life, whereas TGF- $\beta$ subfamily members mainly modulate the immune response (Kingsley, 1994; Hogan, 1996; Letterio \& Roberts, 1998). TGF- $\beta$-like molecules resembling the BMP subfamily members have been identified in molluscs, nematodes, insects, echinoderms, and urochordates (ref. in Beschin et al., 2001). Since the identified invertebrate TGF- $\beta$ and TGF- $\beta$-receptor-like proteins are closer to the mammalian BMP subfamily than to the TGF- $\beta$ one, they may not be involved in immune responses in invertebrates. The molecules involved in the development of invertebrates may have diversified and been recruited by the immune system with the emergence of vertebrates. The example of invertebrate cytokines raises the question whether the immune system arised convergently from different ancestral systems, by diversification from a common ancestor, or by a combination of both routes.

\section{Serine proteinase cascades}

Serine proteinases appeared early in evolution (trypsincoding genes have been found in bacteria) (Rypniewski et al., 1994) and occur in the digestive system of all animals. Proteinases evolved towards fulfilling various advanced physiological functions in the immune and other systems. In the activation of the prophenoloxidase system that leads to melanization in insect haemocytes, a serine proteinase cascade is involved showing similarities to the blood clotting system and the complement system of vertebrates. Proteases organized into cascades mediate dorsal-ventral differentiation, arthropod haemolymph clotting, vertebrate blood clotting, and complement activation. Krem and Di Cera (2002) showed (Fig. 1) that each cascade has a functional core consisting of three serine proteases, the downstream one cleaving the terminal substrate. It seems that the two others, middle and upstream proteases, were added later in evolution. The middle (factor B) and downstream (proclotting enzyme) proteases of the horseshoe crab haemolymph cascade share sequence homology with the Snake (middle protease) and Easter (downstream protease) agents of the Drosophila dorsal-ventral polarity controlling cascade. Factor C (the upstream protease) of the horseshoe crab haemolymph cascade (Muta et al., 1991) has homology to vertebrate complement factors $\mathrm{C} 1 \mathrm{r}$ and $\mathrm{C} 1 \mathrm{~s}$ (upstream and middle proteases) (Kusumoto et al., 1988). Factors $\mathrm{C} 1 \mathrm{r}$ and $\mathrm{C} 1 \mathrm{~s}$ have functional and sequence similarity to scolexin, a haemolymph serine protease of Manduca sexta. This suggests that these proteins had a common ancestor. Thus, the arthropod and vertebrate immune systems use molecules from a pool existing before the protostome-deuterostome split.

The downstream protease of the vertebrate clotting cascade, thrombin, belongs to the same lineage as the complement factors $\mathrm{C} 1 \mathrm{r}$ and $\mathrm{C} 1 \mathrm{~s}$. The upstream and middle proteases of the clotting cascade (factors VII, IX,
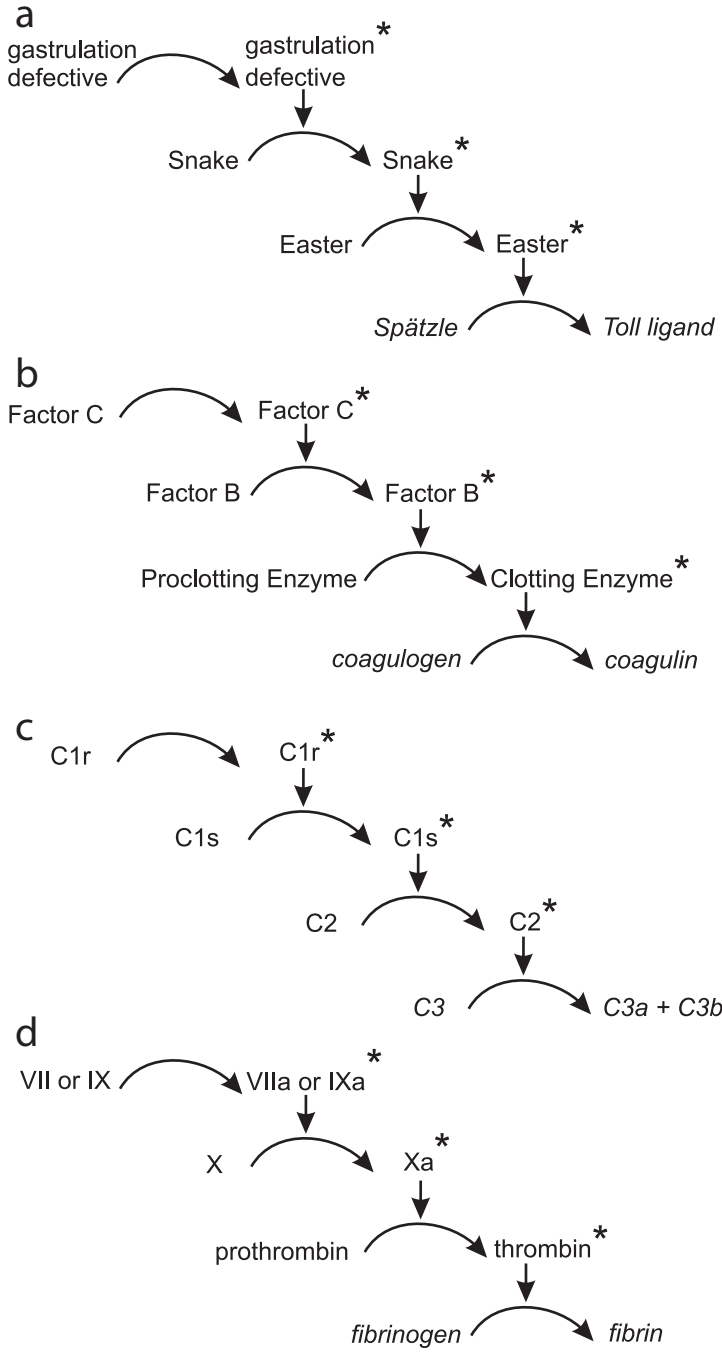

Figure 1. Serine protease cascades of different functions.

Shown are cascades governing dorsal-ventral differentiation during Drosophila embryogenesis (a), horseshoe crab haemolymph clotting (b), classical pathway of complement activation (c), vertebrate blood clotting (d). In evolution, these cascades expanded by adding homologous proteins at the beginning of the cascade. Activated proteases are marked with asterisks. Substrates are indicated with italics. Based on Krem and di Cera (2002).

$\mathrm{X})$ belong to the lineage of the horseshoe crab clotting factor C. This suggests that the vertebrate blood clotting emerged as a by-product of innate immunity, because its entire functional core shares ancestry with the complement proteases. According to Krem and Di Cera (2002), the haemolymph clotting cascades evolved in protostomes after dorsal-ventral cascade with introduction of the complement-like clotting horseshoe crab factor C. In the deuterostomes, a primitive complement system increased its complexity and then blood clotting proteases diverged from the serine proteases of advanced complement system.

There are many functional links between development, immunity, and haemostasis in vertebrates. Enzymes of the coagulation cascade participate in immunity, cell growth and embryogenesis. Various serine proteases belonging to the coagulation system are able to activate the complement cascade independently of the established pathways (Amara et al., 2008). On the other hand, MASP2 a (lectin pathway) is capable of promoting fibrinogen turnover by cleavage of prothrombin generating thrombin (Krarup et al., 2007). Thrombin and 
prothrombin are known to influence the immune reactions. Thrombin induces, for instance, chemotaxis of monocytes and neutrophils. Prothrombin promotes cell migration through the extracellular matrix (ref. in Krem \& Di Cera, 2002). In protostomes, a relation between the clotting cascade and the primitive complement system also exists. Factor $\mathrm{C}$ (the horseshoe crab haemolymph cascade) acts as an LPS-responsive C3 convertase in the initial phase of horseshoe crab complement activation (Ariki et al., 2008). Also, substrates of these four protease cascades show evolutionary relations. Spätzle is structurally homologous to coagulogen. The C-terminal domains of Spätzle and coagulogen share structural homology with the nerve growth factor (NGF) indicating that substrates involved in clotting, immunity and development share common ancestry.

\section{THE BEGINNING OF THE COMPLEMENT SYSTEM}

The vertebrate proteins that bind pathogen or foreign molecules (antigens) and initiate a cascade of events eventually leading to opsonization or lysis of the invader are called complements. Their ancestry is rooted within the invertebrates. In mammals, the complement consists of about thirty soluble proteins directly involved in immune reactions and their regulation. Most are normally inactive and their activation may be triggered directly by an invading organism or indirectly by an immune response. Components $\mathrm{C} 1$ to $\mathrm{C} 4$ are proenzymes activated sequentially by limited proteolytic cleavage. Eventually, the components C5-C9 assembly into a large protein membrane attack complex (MAC) that mediates microbial cell lysis. Thus the activation of complement is focused on microbial cell membrane, where it is triggered either by the antibody bound to the microorganism (classical pathway), by microbial envelope polysaccharides (alternative pathway), or by host proteins binding microbial surface (lectin pathway). Each of these pathways has been studied in detail and they are now part of the textbook knowledge of immunology (Fig. 2).

\section{Ancestry of the complement system}

A large family of thioester-containing proteins characterized by the possession of an internal thiol ester bond within the conserved GCEEQ motif whose covalent bonding to external targets is essential for the function of the protein (Armstrong, 2006). The protease inhibitor $\alpha_{2}$-macroglobulin, the thioester proteins (TEPs), and components C3, C4, and C5 of the complement system belong to this family.

$\alpha_{2}$-Macroglobulin is an opsonin that promotes binding and endocytosis of diverse enopeptidases to cell surface receptors such as the low density lipoprotein-related protein (LRP) (Strickland et al., 1990). In this process, the target protease is enclosed in a molecular cage of the $\alpha_{2}$-macroglobulin polypeptide chain (Borth, 1992; Armstrong, 2006). The bound proteases are degraded in secondary lysosomes (Van Leuven et al., 1978). A variety of mammalian cell types, including monocytes/macrophages, bind the protease $-\alpha_{2}$-macroglobulin complex. Members of the $\alpha_{2}$-macroglobulin protein family have been found within metazoans (ref. in Armstrong, 2006). Initially, it was believed that C3 and $\alpha_{2}$-macroglobulin diverged from an $\alpha_{2}$-macroglobulin-like ancestor. Recently, four genes of thioester-containing proteins (TEPs) have been identified in the cnidarian Haliplanella lineata (Fujito et al., 2010). Two of them are clasified to the $\alpha_{2}$-macroglobulin subfamily and

\section{Classical pathway Lectin pathway Alternative pathway}

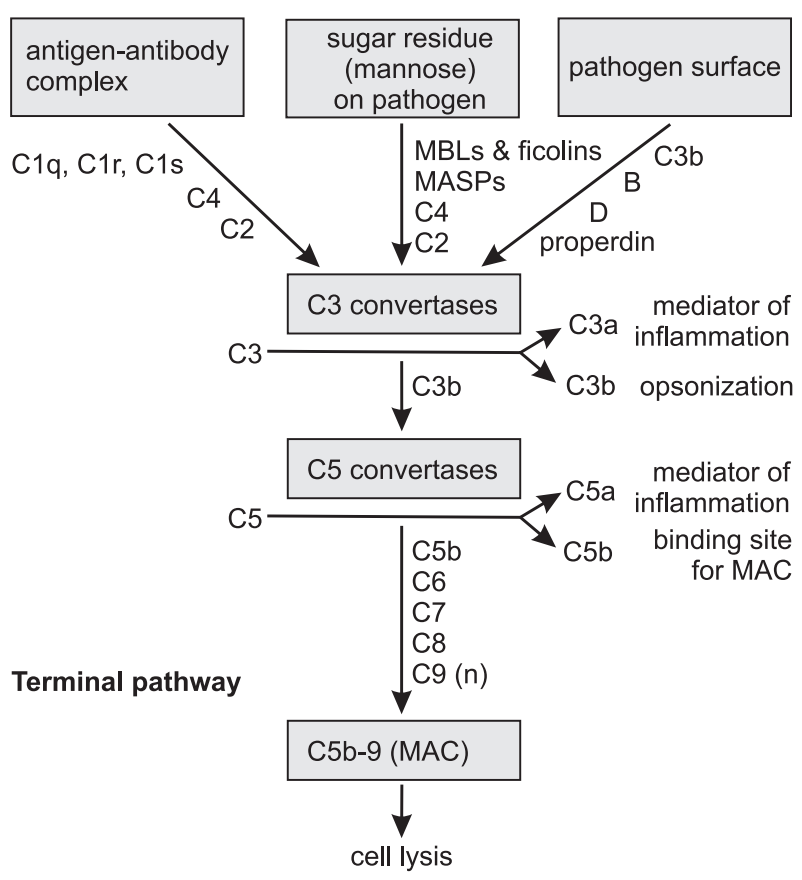

Figure 2. Complement activation pathways

Classical pathway is initiated when C1 component binds to antigen-antibody complexes. C1 consists of $\mathrm{C} 1 \mathrm{q}$ and two copies of $\mathrm{C} 1 \mathrm{r}$ and $\mathrm{C} 1 \mathrm{~s}$ each. As a result of this binding, activated C1q $\mathrm{r}_{2} \mathrm{~S}_{2}$ (C1s and $\mathrm{C} 1 \mathrm{r}$ are serine protease enzymes) cleaves $\mathrm{C}_{4}$ and C2. Alternative pathway is initiated by binding of spontaneously generated C3b to activating surfaces such as microbial cell walls and involves factor $B$, factor $D$ and properdin. Lectin pathway is initiated by binding of the serum protein mannose-binding lectin, MBL (member of collectin family) to the surface of pathogen. After MBL binds carbohydrate residues on pathogen surface, MBLassociated serine proteases (MASP-1 and MASP-2, structurally similar to $\mathrm{C} 1 \mathrm{r}$ and $\mathrm{C} 1 \mathrm{~s}$ ) bind to MBL. Resulting active complex causes cleavage and activation of C4 and C2. All three pathways generate $\mathrm{C} 3$ and $\mathrm{C} 5$ convertases and produce $\mathrm{C} 5 \mathrm{~b}$ which is converted into membrane attack complex by a common sequence of terminal reactions (assembly of components C5b through C9).

the other two genes to the C3 subfamily. The C3 and $a_{2}$ macroglobulin genes are expressed in different parts of the the anemone body. Some characteristics which are found in the human C3, but not in human $\alpha_{2}$-macroglobulin, were present in the common ancestor of the TEP genes. It concerns, for instance, possible cleavage site for C3 convertase, or the catalytic His residue. Their acquisition was believed to be an achievement of C3 subfamily evolution, as it greatly increases the rate of reaction of the thioester with hydroxyl groups and with water (Dodds \& Law, 1998). It is still not clear whether the common ancestor had a C3-like function or an $\alpha_{2}$-macroglobulin-like function. To resolve this problem, animals presenting the state before the $\mathrm{C} 3 / \alpha_{2}$ macroglobulin gene duplication should be found (Fujito et al., 2010). No TEP gene has been identified in sponges and choanoflagellates (Kimura et al., 2009) suggesting that TEPs arose in eumetazoan lineage. Thus, the creation of the TEP gene and subsequent gene duplication and functional differentiation into C3 and $\alpha_{2}$-macroglobulin had to occur after the divergence of sponges and before the divergence of cnidaria from the bilateralia lineage.

Insect TEPs (Blandin \& Levashina, 2004) show functional and structural similarity to members of the C3 subfamily. Some insect TEPs bind bacteria and promote phagocytosis (Levashina et al., 2001) and therefore are reffered to as complment-like proteins. But according to 
Fujito et al. (2010) they belong to the $\alpha_{2}$-macroglobulin subfamily, which suggests that the functional similarity of the arthropod TEPs and mammalian C3 results from functional convergence.

In view of the foregoing, the complement system has a more ancient evolutionary origin than the acquired immunity. Genes encoding proteins with domains typical for complement components, the complement control protein (CCP), von Willebrand factor type A (vWA), serine protease (SP), CUB domain, epidermal growth factor-like (EGF-like), thrombospondin type 1 repeats (TSP), low-density lipoprotein receptor domain class A (LDLa), and SRCR are present in the cnidarian genome (Kimura et al., 2009). As mentioned earlier, the simplest metazoans, sponges, contain proteins with SCR/CCP domains that show high homology to members of the mammalian regulators of complement activation (RCA family) (Pahler et al., 1998). Also, in marine chelicerates the N-terminal region of factor C (serine protease zymogen involved in haemolymph clotting) contains five SCR repeats and is classified into the branch of the family consisting of complement factors initiating complement activation (MASP/C1r/C1s) (Iwanga \& Kawabata, 1998).

The multi-component complement system comprising at least the central molecule of the complement system (C3), Bf, and MASP occurs in the cnidarians (Kimura et al., 2009). While retaining several ancestral features, the cnidarian C3 and Bf genes show close similarity to those of chordates (amphioxus) rather than to those of other invertebrates. This suggests that the ancestral amino-acid sequences of these complement components are well conserved in the cnidarians and chordates. A recurrent loss of complement genes seems to have occurred in other group of cnidaria, Hydra, Caenorbabditis, Drosophila, and the snail Euphaedusa.

The cnidarian complement genes show endodermal cell-specific expression, thus a connection with the gut. The unexpectedly ancient origin of the multi-component complement system can thus be traced back to before the divergence of the cnidarian and bilaterian lineages, perhaps more than 600 million years ago (Ayala et al., 1998). Thus, it is likely that the complement system arose in their common ancestor by the de novo creation of the C3/TEP gene and the establishment of the domain composition of Bf and MASP genes by shuffling of pre-existing domains. The finding of the MASP gene in non-chordates is particularly important, indicating that the lectin pathway is equally old as the alternative pathway.

In echinoderms, the C3 and C2/factor B-like components are present (Smith et al., 2001). In the urochordates, occupying a position between the invertebrates and vertebrates, proteins involved in the lectin and alternative activation pathways, such as glucose-binding lectin (GBL) homologous to mannose-binding lectin (MBL) (Sekine et al., 2001), ficolins (Kenjo et al., 2001), MBL-associated serine proteases (MASPs) (Ji et al., 1997), C3 (Nonaka et al., 1999), and C2/factor B (Nonaka \& Miyazawa, 2002) have been identified. Mannosebinding lectin (MBL) and ficolin are lectins composed of a lectin domain attached to a collagen-like region. Their structure is similar to that of complement $\mathrm{C} 1 \mathrm{q}$ owing to the collagen-like stalk. However, they use a different lectin domain for carbohydrate recognition: a carbohydrate recognition domain (CRD) is found in MBL and a fibrinogen-like domain in ficolin. Glucosebinding lectin (GBL) contains a carbohydrate recognition domain that is homologous to C-type lectin. The collagen-like domain is replaced in this molecule by another sequence that has a helical structure similar to the configuration of the Gly-X-Y repeats of collagens. Ficolins as well as GBL probably act as recognition molecules of the primitive urochordate complement system in a similar manner to the mammalian lectin pathway. Complement-mediated phagocytosis is a central part of the physiological function of the urochordate complement system.

The jawless fishes of the class Agnatha (lamprey and, even more primitive, hagfish) are the least derived of all extant vertebrates. C3 from the hagfish Eptatretus originally identified as hagfish Ig (Varner et al., 1991), apparently has a two-chain structure containing a thioester site in the $\alpha$ chain. It acts as an opsonin (Hanley et al., 1992). A protein from the lamprey homologous to mammalian C3/C4 (Nonaka \& Takahashi, 1992) has been shown to have opsonic activity as well. The sequence of factor B (alternative activation) from lamprey is equally similar to those of mouse factor $\mathrm{B}$ and $\mathrm{C} 2$, suggesting that it represents a stage before the $\mathrm{Bf} / \mathrm{C} 2$ gene duplication (Nonaka et al., 1994). Two lectins from lamprey serum (Endo et al., 2006) have been identified: an MBL and a homologue of C1q. Both lectins are associated with a serine protease of the MASP family (MASP-A) which exhibits a proteolytic activity against lamprey C3. The single MASP molecule found in the lamprey (Matsushita et al., 2004) appears to be more related to the MASP2 isoform found in other animal species. The lamprey C1q consists of a collagen-like domain and an antibody recognition domain, $\mathrm{gCl} \mathrm{q}$, found in a variety of proteins including mammalian C1q. In a phylogenetic tree of the gC1q domains lamprey $\mathrm{C} 1 \mathrm{q}$ and mammalian $\mathrm{C} 1 \mathrm{q}$ form a cluster. These observations strongly suggest that $\mathrm{C} 1 \mathrm{q}$ may have emerged as a lectin and functioned as an initial recognition molecule of the complement system before the appearance of acquired immunity components, such as immunoglobulins, in the cartilagineous fishes. Therefore, the lamprey complement system consists of at least the lectin MASP complex and C3. However, identification of lamprey $\mathrm{C} 1 \mathrm{q}$ clearly indicates that the classical pathway originates at the agnathan stage.

There is no evidence for the presence of the membrane attack complex (MAC) in lamprey (Fujii et al., 1992), although a single component with lytic activity has been described in lamprey serum. However, a gene with sequence similarity to the mammalian complement membrane attack regulatory molecule CD59 (protectin) has been reported in the hagfish (dos Remedios et al., 1999). The presence of this gene suggests that the terminal lytic complement pathway (C5b-9) could operate in these primitive vertebrates. Thus, the agnathan complement represents an early intermediate stage in the complement phylogeny. It is worth noting that in the anthozoan cnidarians, several proteins with membrane attack complex/perforin domain have been found (Miller et al., 2007).

\section{EVOLUTION OF THE COMPLEMENT SYSTEM}

There is empirical evidence that the complement system increased in complexity while evolving from the fish to mammalian grade.

\section{Cartilagineous fishes}

Sharks are the most primitive vertebrates having partial molecular machinery required to mount an adaptive 
immune response, i.e., antibodies (Schluter et al., 1997), TCR (Rast \& Litman, 1994), and MHC class I and II molecules (Salter-Cid \& Flajnik, 1995). In addition, they possess the simplest form of the classical pathway of complement activation, not present in jawless fishes. The nurse shark Ginglymostoma (Jensen et al., 1981) has six complement-like proteins that interact sequentially and form functional cascades corresponding to the mammalian classical and lytic pathways. Shark C1q is composed of at least two chain types with $50 \%$ identity to human C1q A and B chains. MASP genes (lectin pathway) known from two shark species show greater homology to mammalian MASP-2/C1r/C1s lineage than to MASP2 (Smith, 1998). Moreover, the presence of a functional alternative pathway as well as of proteins resembling C3, factor $\mathrm{B}$, and a putative factor $\mathrm{H}$, a regulator of complement activation in the alternative pathway (Dodds et al., 1998; Shin et al., 2007), was assessed. The presence of a lytic pathway in sharks is postulated on the basis of the isolation of $\mathrm{C} 8$ and $\mathrm{C} 9$ in the shark, although the molecular mass of those proteins (185 and $200 \mathrm{kDa}$, respectively) is higher than those of their mammalian counterparts (Smith, 1998).

\section{Bony fishes}

The complement system of the teleosts covers all three pathways of complement activation and involves $\mathrm{C} 1 \mathrm{r} / \mathrm{C} 3 / \mathrm{C} 4 / \mathrm{C} 5 / \mathrm{C} 8 / \mathrm{C} 9 / \mathrm{fB} / \mathrm{fD} / \mathrm{fH} / \mathrm{MASP} / \mathrm{MBL}-$ like molecules (Zarkadis et al., 2001). However, the complement function in these fishes differs in a number of important aspects from that in mammals. As could be expected, the optimal activation temperature for fish complement is much lower $\left(20-25^{\circ} \mathrm{C}\right)$ than in the mammals $\left(37^{\circ} \mathrm{C}\right)$. Furthermore, in contrast to the human complement, complements from a variety of fishes can lyse erythrocytes of tetrapodes and humans with high efficiency through activation of the alternative pathway. Because the antibody response in fishes is quite rudimentary, it is postulated that the complement in these species may act against invading pathogens. Some of the components (C3 and factor B) of the complement system of bony fishes are present in multiple isoforms encoded by different genes. The most important feature of these $\mathrm{C} 3$ isoforms is that they differ in their binding specificities for a number of complement-activating surfaces. All the purified C3 isoforms were found to contain an $\alpha$ and $\beta$ chain and to have an internal thioester bond in the $\alpha$ chain (ref. in Zarkadis et al., 2001).

In the trout Salmo factor Bf-2 acts in both the classical and alternative pathways of complement activation. They may represent primordial molecules that in warm-blooded vertebrates have evolved to function exclusively in either the alternative or classical pathways. This suggests that before the divergence of $\mathrm{C} 2$ and factor B from the common ancestor, a molecule existed that was able to function in both the alternative and classical pathways. The presence of factor B-like molecules in urochordates, agnatha, sharks and teleosts, as well as the absence of C2-like molecules from those species, provide evidence that the $\mathrm{fB} / \mathrm{C} 2$ duplication and the appearance of $\mathrm{C} 2$ took place after the divergence of teleosts (Zarkadis et al., 2001). In teleost fishes, two MASP-3 and two C1r/ C1s/MASP-2-like isotypes have been found (Nakao et al., 2003b). They are structurally similar to each other, belonging to the MASP/C1r/C1s family comprising MASP-1-like and MASP-2/C1r/C1s-like proteins (Thiel et al., 1997; Matsushita et al., 1998). The exact point of divergence of MASP-1 and MASP-2/C1r/C1s within the lower vertebrates remains unclear. As suggested by studies on urochordates, MASP-1 may have emerged prior to MASP-2/C1r/C1s (Nonaka, 2001). Thanks to the cloning of cnidarian complement genes (Kimura et al., 2009) it is known that the cnidarian MASP shares with invertebrate MASPs and vertebrate MASP-1 some canonical features of the serine protease (SP) domain which were lost in vertebrate MASP-2, MASP-3, C1r and C1s, indicating that the ancestral MASP was MASP-1 type molecule. The $\mathrm{C} 1 \mathrm{r}$ and $\mathrm{C} 1 \mathrm{~s}$ components of $\mathrm{C} 1$ are clearly derived from the MASP lineage. C1q is closely related to MBL or ficolins with the substitution of antibody recognition domains for the CRDs in MBL or fibrinogen-like domain in ficolins. Two C1 genes from the carp Cyprinus with $36 \%$ and $34 \%$ homology to human $\mathrm{C} 1 \mathrm{r}$ and $\mathrm{C} 1 \mathrm{~s}$, respectively, may be close to ancestors of the mammalian C1r/C1s (Nakao et al., 2001). From the evolutionary point of view, the primitive lectin pathway in innate immunity appears to have developed into the more sophisticated, multifunctional complement system of the classical pathway through gene duplication, to serve as an effector system of acquired immunity.

\section{Terminal complement components - lytic pathway}

Molecules homologous to mammalian C5 have been described in several species of teleost fishes (ref. in Zarkadis et al., 2001). Although C5 is closely related to $\mathrm{C} 3$ and $\mathrm{C} 4$, it seems that the other components of the lytic pathway (C6, C7, C8a, C8b, and C9) are related and homologous to perforin, the lytic protein of natural killer cells and cytotoxic lymphocytes (Podack et al., 1989). All these molecules share common structural motifs, i.e., thrombospondin (TS), low-density lipoprotein receptor (LDL-R), and epidermal growth factor precursor (EGFP) domains. In addition, C6 and C7 possess short consensus repeats (SCRs) and FIM modules in the C-terminal domain. The cloning of a C6-like gene from the most primitive of present-day chordates, the amphioxus Branchiostoma, suggests an ancient origin of the C6/ $\mathrm{C} 7 / \mathrm{C} 8 / \mathrm{C} 9 /$ perforin gene family. Sequence analysis studies suggest that $\mathrm{C} 6$ and $\mathrm{C} 7$ emerged first, followed by the appearance of C8 and C9 (Mondragon-Palomino et al., 1999). It seems reasonable that the duplication of an ancestral gene proceeded through two pathways. One pathway presumably led to the simple form of perforin, while the second produced the ancestor of C6-C7 with its complex modular structure. Further duplication and loss of modules may have led to the creation of C8 and C9 molecules. Following the emergence of cyclostomes, a primitive lytic pathway appeared. The membrane attack complex present in teleost fish closely resembles the mammalian complex.

\section{Complement regulatory proteins}

The survival of hosT-cells requires their protection from autologous complement attack. Various regulatory molecules belong to a human gene family of regulators of complement activation (RCA) (Hourcade et al., 1989). Each of these proteins is composed exclusively of short consensus repeats (SCRs) (also known as complement control protein modules CCPs), and their binding to the active complement fragments $\mathrm{C} 4 \mathrm{~b} / \mathrm{C} 3 \mathrm{~b}$ inhibits activation of the complement pathways. Complement regulatory-like molecules with SCR domains, probably close to ancestors of the RCA gene superfamily, have been found in urochordates ( $\mathrm{Li}$ et al., 2000). Also, identification of soluble regulatory proteins of the complement 
system such as lamprey C4-bp (Kimura et al., 2004) and factor $\mathrm{H}$ (Endo et al., 2006) has led to the suggestion that the lamprey complement system may be more sophisticated than the urochordate system. Two isotypes of complement regulatory factor I (Nakao et al., 2003a) and factor $\mathrm{H}$ have been cloned and characterized in teleost fish (Krushkal et al., 1998). A GPI-anchored membrane protein (CD59, also called protectin) is the main regulatory molecule protecting hos'T-cells from the lytic attack of terminal complement complexes (MAC) (Morgan, 1999). A CD59-like gene from the trout (Salmo) has high sequence similarity to mammalian CD59 (Lee \& Goetz, 1998). A gene encoding a CD59-like molecule has also been cloned from the hagfish. The presence of CD59 in the hagfish, together with the observation of a C5a-like activity in hagfish plasma, suggests that an ancient form of the lytic pathway is present in these primitive vertebrates (dos Remedios et al., 1999).

According to Nonaka and Kimura (2006) the evolution of the complement can be summarized as follows: A primitive complement system most likely composed of $\mathrm{C} 3$ and $\mathrm{Bf}$ and thus similar to the mammalian alternative pathway emerged in the common ancestor of cnidaria and bilaterians. The structural features of these cnidarian genes suggests that the ancestral C3 was proteolytically activated by $\mathrm{Bf}$, and that it formed a covalent bond with non-self molecules using its intramolecular thioester bond. Whereas the $\mathrm{C} 3$ and $\mathrm{Bf}$ genes were retained by deuterostomes, they were lost many times independently in the protostome lineages. The recent finding of a MASP gene in cnidarians (Kimura et al., 2009) suggest that the primitive lectin pathway could operate besides the alternative pathway in those animals. MASP, MBL, and ficolin constitute the urochordate lectin pathway similar to the mammalian one. Finally, vertebrate-specific complement gene duplications, such as those leading to $\mathrm{C} 3 / \mathrm{C} 4 / \mathrm{C} 5, \mathrm{Bf} / \mathrm{C} 2$ and $\mathrm{MASP} / \mathrm{C} 1 \mathrm{r} / \mathrm{s}$, occurred before the emergence of cartilagineous fish, most probably contributing to the establishment of the third activation pathway, the classical pathway. The classical and lytic pathways of the complement system seem to have emerged at the cartilagineous fish stage, coincident with the emergence of adaptive immunity. Genes for the ancestral terminal complement components appear to have been recruited by the complement system and duplicated to $\mathrm{C} 6 / \mathrm{C} 7 / \mathrm{C} 8 \mathrm{a} / \mathrm{C} 8 \mathrm{~b} / \mathrm{C} 9$ before the appearance of the jawed vertebrates, although the timing of those events still needs to be clarified in detail.

\section{ALLORECOGNITION}

Although only jawed vertebrates possess major histocompatibility complex MHC, allorecognition is well documented in urochordates and non-chordate invertebrates. All urochordates seem to have natural killer (NK) cells involved in allorecognition (Kasahara et al., 2004). One of the urochordate Botryllus genes whose expression is down-regulated after allogenic contact is a homologue of CD94/NKR-P1 (natural killer cell receptor, $\mathrm{P} 1$ ); this gene is expressed in the blood cells of Botryllus (Khalturin et al., 2003). Natural killer cell receptors are, however, unrelated to the MHC, use also other ligands than MHC, are not involved directly in AIS, and are not an evolutionarily homogenous group. De Tomaso et al. (2005) have found that in Botryllus allorecognition is determined by a single genetic locus, FuHC (for fusibility/ histocompatibility). Fusion occurs when two colonies share at least one FuHC gene variant, or allele; rejection occurs when no FuHC alleles are shared. A gene encoding an immunoglobulin superfamily member was isolated that, by itself, determines the outcome of histocompatibility reactions (De Tomaso et al., 2005). This gene is believed to encode epidermal growth factor repeats and also immunoglobulin domains. However, $\mathrm{cFuHC}$ is not homologous to any proteins of the vertebrate MHCbased histocompatibility system (Klein, 2006); for example, the immunoglobulin domains do not correspond to the $\mathrm{C} 1$ type found in $\mathrm{MHC}$. $\mathrm{cFuHC}$ has high homology with human IGSF4, the more ancient immunoglobulin domains, which may be descendents of the first antigen receptors (Du Pasquier et al., 2004; Cannon et al., 2004). According to Laird et al. (2005), the function of FuHC may be to protect against parasitism by conspecific stem cells. The genome of the related urochordate Ciona harbours a number of genes highly homologous to those involved in natural killing in vertebrates (Azumi et al., 2003) but not homologues of the $c F u H C$ gene. A transmembrane protein that has three short consensus repeats (SCR) domains termed variable complement receptorlike protein 1 (vCRL1) is expressed in follicle cells and haemocytes of Ciona. This protein is strikingly variable between Ciona individuals. In the urochordate Halocynthia, the putative self sterility protein is a transmembrane receptor (HrVC120) expressed on oocytes. It has 12 EGFlike domains and one zona pellucida domain. These EGF-like repeats also show genetic polymorphism between Halocynthia individuals. One may hypothesize that the self-recognition required during fertilization co-opted a subset of complement molecules from a defense pathway. Apparently, each of the three urochordates studied (Ciona, Botryllus, Halocynthia) employs completely different molecules to distinguish self from non-self (Khalturin \& Bosch, 2007).

\section{MAJOR HISTOCOMPATIBILITY COMPLEX}

In vertebrates, allorecognition depends on proteins encoded by major histocompatibility complex (MHC) genes. In higher vertebrates $\mathrm{MHC}$ is represented by two distinct classes, MHC I and MHC II. A candidate for the primordial MHC gene is not known. Molecular phylogenetic analysis supports a relationship between the class II MHC $\alpha$ chain and class I $\beta_{2}$-microglobulin and between the class II MHC $\beta$ chain and class I $\alpha$ chain. The most likely hypothesis is that the ancestral MHC molecule had a class II-like structure and later gave rise to a class I molecule (Hughes \& Nei, 1993; Klein \& O'hUigin, 1993), although now class I is more widely distributed, being expressed on most nucleated cells, whereas class II is restricted to B-cells, macrophages and dendritic cells. The plasma membrane cell adhesion proteins (N-CAM) involved in ontogenic organogenesis is probably ancestral to the adaptive immune system. N-CAM of chicken neuronal organogenesis possesses four $\beta_{2}$-microglobulin-like domains, and it is this domain from which the adaptive immune system possibly originated (Ohno, 1987). An MHC-like region is certainly very ancient and is believed to be present in the common ancestor of proto- and deuterostomes (Danchin et al., 2003). The human genome contains at least three MHC-like paralogous regions (Flajnik \& Kasahara, 2001). It has been proposed that the MHC region arose as a result of chromosomal duplications. Phylogenetic analysis shows that all duplication events in those regions occurred after the split of 


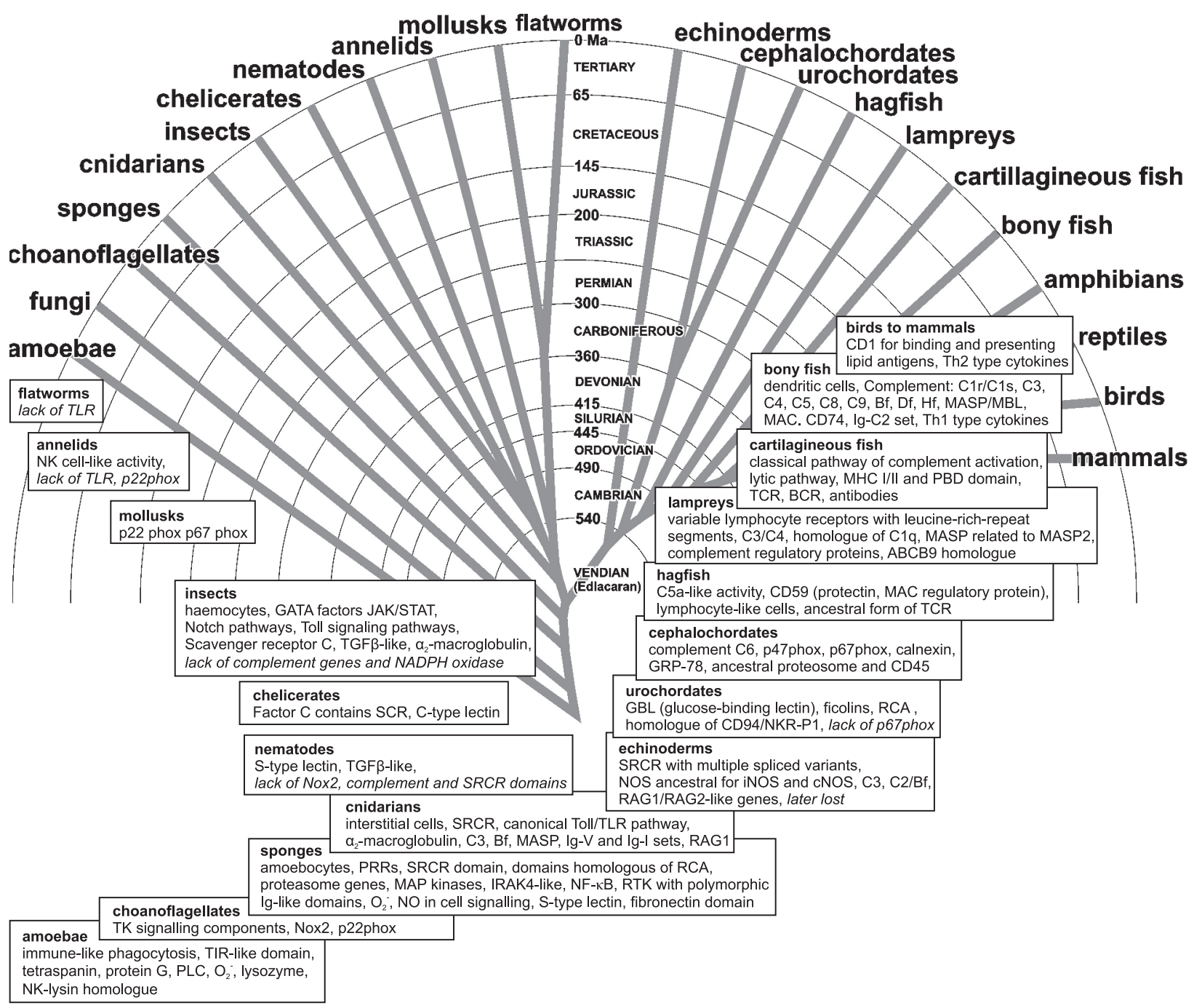

Figure 3. Cumulative pattern of introduction of immunity mechanisms in the evolution of animals.

First appearance of molecules or processes is superimposed on phylogenetic relationships among major taxa referred to in the text, with special emphasis on most ancient events.

Abbreviations: MAC, membrane attack complex; NK-lysin, natural killer cell-lysin; NOS, nitric oxide synthase (inducible or constitutive isoforms); Nox, phagocyte NADPH oxidase; PLC, phospholipase C; PRRs, pattern recognition receptors; RAG, recombination activating genes; RCA, regulators of complement activation; RTK, receptor tyrosine kinase; SCR, short consensus repeats; SRCR domain, scavenger receptor cysteine-rich domain; TIR, Toll, interleukin-1 receptor, and plant disease resistance genes; TK, tyrosine kinase.

the agnathans but before the origin of gnathostomes (Klein, 1986; Kasahara et al., 1997). Perhaps the duplication allowed one copy of the genes to preserve their houskeeping function and the other copy to diversify.

Vertebrate MHC-based histocompatibility is thought to be a by-product of peptide presentation and polymorphism. The function of MHC is to present peptides (antigens in general) to $\mathrm{T}$-cell receptors. The immune system uses different pathways to eliminate intracellular and extracellular antigens. As a general rule, endogenous antigens (those generated within the cell) are processed in the cytosolic pathway, transported with class I MHC molecules to the plasma membrane of most nucleated cells, and presented on its surface. Exogenous antigens (those taken up by phagocytosis) are processed in the endocytic pathway, transported with class II MHC molecules and presented on the membrane of antigen presenting cells (macrophages, dendritic cells, T-cells).
The peptide-binding domain (PBD) is responsible for the association of the peptide and the MHC molecule. The peptide-binding cleft is formed by the membranedistal domains in both class I and class II MHC. No clear homologue of the PBD module has been found in any non-vertebrate genome (Klein \& Nikolaidis, 2005 and references there). Possibly, it originated by an interdomain exchange. One of the two domains involved in the putative recombination could have been an Ig-like domain (ILD), which contributed a part of its $\beta$-sheet, whereas the $a$-helix could have derived from another domain (e.g., from the phage MS2 coat protein by a transposon-mediated transfer). Not only the $\beta$-sheets of the Ig-like domains resemble the $\beta$-sheet of the peptidebinding domain, but also ILDs constitute the remainder of the extracellular part in the MHC polypeptide, and genes encoding other ILD-bearing molecules are abundantly represented in the MHC region. 


\section{The cytosolic pathway}

The pathway by which endogenous peptides are degraded for presentation with class I MHC molecules (expressed on most nucleated cells) utilizes mechanisms similar to those involved in the normal turnover of intracellular proteins, but how particular peptides are selected remains unclear. The resulting peptides are translocated by the transporter (TAP) to the rough endoplasmic reticulum, which is the site of MHC biosynthesis. In the reticulum, they bind the MHC molecules and the resulting peptide complexes are then transported to the cell surface for recognition by T-cells (Kindt et al., 2007). The assembly of these components into a stable molecular complex involves several steps and includes the participation of molecular chaperones calnexin, calreticulin, and tapasin that facilitate folding of the polypeptides (Watts \& Powis, 1999). An additional protein with enzymatic activity, glucose-regulated protein (GRP58, also called ERP57), forms a disulfide bond to tapasin, and noncovalently associates with calreticulin. This association promotes binding of an antigenic peptide which stabilizes the class I molecule - peptide complex, allowing its release from the rough endoplasmic reticulum (Van Endert, 1999). Calnexin is a transmembrane endoplasmic reticulum chaperone with a lectin activity. Calreticulin is a soluble homologue (paralog) of calnexin; GRP58 is a member of the thioredoxin enzyme family which includes protein disulfide isomerase (PDI) as well. These enzymes catalyze the isomerization of disulfide bonds of proteins undergoing folding and assembly. Phylogenetic analysis shows that calreticulin and GRP58 have homologues in all eukaryotes (Danchin et al., 2003). Vertebrate calnexin and calmegin are orthologues of non-vertebrate calnexin. In vertebrates, calnexin has retained the ancestral function and has directly been co-opted for a new process, while the other duplicate, calmegin, has evolved toward a specific function in sperm fertility (Ikawa et al., 1997).

The transporter associated with antigen processing protein (TAP) is a membrane-spanning heterodimer. TAP belongs to the drug peptide and lipid export (DPL) subgroup of the adenosine triphosphate-binding cassette (ABC) family and is optimized to transport peptides that would interact with class I MHC molecules (Bouige et al., 2002). Within this group TAP1, TAP2, ABCB9 and Mdl1 form a monophyletic group. Mdl1 in yeast, like TAP1 and TAP2, is involved in peptide transport (Young et al., 2001). Phylogenetic analysis shows that TAP1 and TAP2 arose from a duplication of the ancestor of ABCB9/TAP1/TAP2 and that an ABCB9 homologue is present in the lamprey (Uinuk-Ool et al., 2003a). ABCB9 is associated with lysosomes (Zhang et al., 2000) and it is therefore possible that ABCB9 is involved in peptide transport in this organelle. Tapasin is found in all bony vertebrates and probably in all jawed vertebrates, and is a transmembrane protein. Proximal to the transmembrane portion, an IgC1 domain is found, phylogenetically related to class I and class II $\beta$ chains, implying that tapasin was derived from an MHC class II/class I $\beta$-like gene.

The immune system of vertebrates appears to have recruited the proteasome for the proteolytic generation of MHC class I epitopes. These ubiquitous multisubunit endoproteases are phylogenetically ancient, as they are found both in bacteria and eukaryotes. Peptides generated by the proteasome in Drosophila and yeast, which lack MHC function and genes, have a size and composition suitable for loading onto MHC molecules (Niedermann et al., 1997), and therefore it is likely that the product of the proteasome was re-routed towards a new biochemical pathway via the peptide transporters. Agnathans lack the ability to produce immunoproteasomes; like in other eukaryotes, their proteasomes contain 7 isoforms of $\alpha$ subunit and 7 of $\beta$ subunit. In vertebrates, following the in vitro action of interferon- $\gamma$, PSMB5, PSMB6, and PSMB7 (the three proteolytically active $\beta$ subunits), are replaced by their paralogues, immunosubunits, PSMB8, PSMB9, and PSMB10, respectively. After the gene duplication events, it seems that PSMB5, PSMB6, and PSMB7 kept their ancestral molecular behavior (protein degradation), while PSMB8, PSMB9, and PSMB10 evolved toward the production of specific peptides for MHC presentation (Danchin et al., 2003). Genes for PSMB and TAP proteins are still evolving divergently under selective pressure in different vertebrate lineages (Nonaka et al., 2000; Powis et al., 1992).

\section{The endocytic pathway}

The second location for proteolysis involves the endosomal/lysosomal compartments, where proteases digest any external or internal proteins that find their way into these organelles acquired through immune surveillance of exogenous pathogens. Similarly to class I, class II MHC molecules are assembled within the rough endoplasmic reticulum, where they associate with a transmembrane glycoprotein called invariant chain (Ii, CD74). The bound invariant chain prevents premature binding of any endogenously derived peptides, while the class II molecule is within the reticulum and helps to direct the complex to endocytic compartments containing peptides derived from exogenous antigens. Inside the loading compartments, CD74 is digested by cathepsins S and $\mathrm{L}$, which leaves the binding fragment (CLIP). The removal of CLIP and peptide loading require an endosome-resident accessory molecule HLA-DM. In mammalian B-cells, peptide loading is further modulated by another molecule, HLA-DO. These molecules belong to the non-classical MHC class II family (Hiltbold \& Roche, 2002).

The invariant chain glycoprotein CD74 is found only in the gnathostome vertebrates (Dijkstra et al., 2003); several cathepsins seem to have been co-opted for MHC class II peptide presentation several times during evolution (Uinuk-Ool et al., 2003b), at the level of exogenous peptide processing and processing of CD74. As for the cytosolic pathway system, the housekeeping chaperones such as calnexin (remains bound to incomplete complexes) are found in all eukaryotes; therefore, they probably have been recruited directly by the MHC class II system. Some of the proteins involved come from an ancestral duplication that gave rise to classical class II genes and in the other part to HLA-DM (Kasahara et al., 1995). Therefore, classical class II MHC and the chaperone HLA-DM probably come from the major tinkering that happened in the proto-MHC region in the early vertebrate evolution (Abi-Rached et al., 1999).

\section{ANTIGEN PRESENTING}

The function of sampling the environment for pathogens is provided in vertebrates by the lymphoid and myeloid dendritic cells, present in small quantities in various tissues in peripheral regions of the body. Those from the skin are referred to as Langerhans 
cells. Like any other phagocyting cells they constantly sample the environment for viruses, bacteria, or parasites using their pattern recognition receptors to recognize specific chemical signatures of the pathogens. Immature dendritic cells capture them and then migrate to lymph nodes, where they present the antigen to T-cells. Dendritic cells mature after being contacted with antigens, which means that they shift from an antigen-capturing phenotype to one supporting antigen presentation. The chemotactic receptor CCR7 induces the dendritic cell to travel through the blood stream to the spleen or through the lymphatic system to a lymph node (Penna et al., 2002). In the node, the cell-surface receptors of mature dendritic cells act as co-receptors in activation of T-cells; that is they perform their function as antigen-presenting cells to initiate the immune response.

Although originally identified in mammals, dendritic cells are more ancient than tetrapods, as they occur in the epidermis of the teleost bony fish (Wölfle et al., 2009). Birds appear to already possess genes for the family of CD1 proteins (MHC-like genes) (Miller et al., 2005; Salomonsen et al., 2005) with the property of binding and presenting lipid rather than peptide antigens, earlier known only from mammals. In the brown rat (but not mouse), a subset of dendritic cells still exist that display pronounced killer cell-like activity, which seems to reflect conservation of a rather primitive state in their evolution (Trinité et al., 2000).

\section{THYMUS}

The thymus is the only organ of the adaptive immunity system organ present in the gnathostomes and absent in the agnathans. In the thymus, the differentiation of T-cell is regulated by SPI-B, GATA3 and genes of the IKAROS family (ref. in Klein \& Nicolaidis; Suzuki et al., 2004). Among the blood cells of lamprey and hagfish there are lymphocyte-like cells expressing homologues of these genes (Uinuk-Ool et al., 2002 Suzuki et al., 2004). Nevertheless, the agnathan cells do not express the receptor molecules TCR and BCR, thus being not fully equivalent to the gnathostomes lymphocytes (Guo et al., 2009).

The membrane-bound antigen-binding receptor (TCR) of the lymphocytes produced in the vertebrate thymus (T-cells) can recognize only an antigen that is bound to the major histocompatibility complex molecules. The antigen-binding receptors on T-cells are very specific and extremely diverse. This is because in the process of T-cell maturation, a random rearrangement of a series of gene segments that encode the cell's antigen-binding receptor takes place. The mechanism of the rearrangament is similar to that in the reviewed below for B-cells, which is better known. The role of the antigen becomes critical when it interacts with and activates a mature, antigenically committed lymphocyte, bringing about expansion of the population of cells with a given antigenic specificity. In this process of clonal selection, an antigen binds to the particular cell and stimulates it to divide repeatedly into a clone of cells with the same antigenic specificity as the original parental cell. It is a Darwinian mechanism: enormous variation and then selection. The self-non-self discrimination is accomplished by the elimination (during development) of lymphocytes bearing self-reactive receptors or by functional sup- pression of these cells if they reach maturity. The presence of lymphocytes activated and multiplicated via clonal selection provides the basis of immunological memory (Klein \& Nikolaidis, 2005).

The antibody-based immune system is defined by the presence of MHC, TCR, BCR and recombination activating genes, the $\mathrm{R} A G$ genes. It arose after the divergence of the gnathostomes from the agnathans (Takezaki et al., 2003). The origin of the adaptive immunity represents a culmination of a long gradual accumulation of small changes in organs, cells and molecules over hundreds of million years (Klein \& Nikolaidis, 2005).

\section{ANTIBODY-BASED IMMUNE SYSTEM}

About $90 \%$ of animal species have no adaptive immunity, yet they thrive, with many living for decades, in a world of microbes. Presumably the adaptive response provides a competitive advantage to animals equipped with it. They are able to fight pathogens at a much lower cost than is possible with the innate immune system alone.

A membrane-bound antigen-binding receptor (i.e., antibody) on B-cells matured in the birds' bursa Fabricii or in the mammalian bone marrow can recognize a free antigen. The antigenic specificity of each B-cell is determined by its membrane-bound antibodies. As in the case of T-cells, this specificity is created by random rearrangements of a series of gene segments that encode the antibody molecule. All antibody molecules on a given $\mathrm{B}$ lymphocyte have identical specificity. A selection process in the bone marrow eliminates any B-cells with membrane-bound antibody that recognizes self components.

A substantial diversity of immunoglobulin molecules is generated by the RAG1/RAG2 recombinase which catalyses random gene segment rearrangements during early development of the lymphocyte (the primary repertoire). Following antigen encounter, somatic hypermutation triggered by the activation-induced deaminase (AID; an enzyme that deaminates cytosine residues and thus converts them into uracil) occurs yielding a secondary repertoire. A maturing B-cell starts with dozens to hundreds of three classes of gene segments and, as it develops, the cell excises all but one of each class. The surviving segments then get stitched together into a DNA sequence that encodes the antibody unique to each mature B-cell. The T-cell similarly recombines gene segments to create distinc'T-cell surface receptors for pathogens (Travis, 2009). In mammalian B lymphocytes, recombination is followed by further diversification of the BCR genes by two or three mechanisms, depending on species: untemplated somatic hypermutation, pseudogene-templated gene conversion, and switch recombination (Kindt et al., 2007). All three mechanisms rely on the participation of the activation-induced deaminase (Honjo et al., 2004).

Immunoglobulin domains (ILDs), categorized in seven main types (V, C1, C2, C3, C4, I and FNIII), are found in all molecules essential for antibody-based immunity: MHC molecules, TCR, BCR, CD4 and CD 8 coreceptors, and others (Kindt et al., 2007). The presence of immunoglobulin domains in many different proteins involved in the immune response and cell adhesion suggests that these domains have been distributed among different proteins mainly by exon shuffling through intronic recombination. These domains share the basic Ig-fold structure (consisting of two $\beta$-pleated sheets of a sand- 
wich rolled into a cylinder). It is generally accepted that all members of the $\mathrm{Ig}$ superfamily derive from a single common ancestor. However, independent origin by convergent evolution of some of them cannot be excluded (Halaby \& Mornon, 1998). In the genome of the cnidarian starlet see anemone Nematostella, both I type and $\mathrm{V}$ type domains have been found. On the basis of this analysis, it is still not possible to distinguish which is the most ancestral set of immunoglobulin domains (Buljan \& Bateman, 2009). Presently, only these two domains are found in lower invertebrates. The C2 type that includes domains present in the CD4 and CD8 coreceptors and adhesion molecules is known from arthropods (Buljan \& Bateman, 2009). The V-domains of the subtype found in the TCRs and BCRs are known from both agnathans (Pancer et al., 2004) and cephalochordates (Cannon et al., 2002; Sato et al., 2003), although in these they do not rearrange. Thus, the nonrearranging $\mathrm{V}$-type domains arose before the AIS was established. The V-domains of TCRs and BCRs share the rearrangement mechanism, which suggests that they derived from a common ancestral domain, present before the divergence of the extant gnathostome classes (Hood et al., 1985). The species distribution of immunoglobulin domains shows that the C1 type is found only in gnathostome vertebrates and developed late in the metazoan evolution. Many of the immunoglobulin-like domains found in sponges are associated with kinase domains, as it was mentioned earlier, suggesting that the immunoglobulins' ancestral function involved signalling (Buljan \& Bateman, 2009).

The RAG1 protein is a large multifunctional recombinase which binds to specific recombination signal sequences flanking the $\mathrm{V}, \mathrm{D}$, and $\mathrm{J}$ gene segments, cleaves the DNA between these sequences and the coding sequence, opens hairpins formed by the broken ends, joins the broken DNA ends and acts as transposase, at least in vitro. The RAG2 protein seems to act primarily as a stabilizing cofactor of RAG1. The RAG proteins are not closely related to any other eukaryotic recombinase (Agrawal et al., 1998). It has been proposed that these RAG enzymes were originally transposons, for instance a Transib family of DNA transposons (Kapitonov \& Jurka, 2005), which, however, do not contain sequences related to a RAG2 protein, or arose by insertion of an infectious DNA virus resembling a herpes virus adjacent to a sequence encoding a RAG2 protein (Dreyfus, 2009), but this transposon theory remains controversional (Hughes, 1999). In the genome of the purple see urchin genes that closely resemble $R A G 1$ and $R A G 2$ have been found (Rast et al., 2006). Suprisingly, the cnidarian genomes encode a protein related to deuterostome RAG1 (Hemmrich et al., 2007). The occurrence of RAG proteins in echinoderms suggests that the putative transposon encoding these enzymes invaded early deuterostomes to be subsequently lost in most their lineages except for the jawed vertebrates, which adopted them to perform the VDJ recombination (Travis, 2009).

Activation-induced deaminase (AID) is a member of a vertebrate family of related enzymes which perform a variety of functions (Beale et al., 2004). For instance, proteins of this family are related to RNA-editing enzymes in yeast (Xie et al., 2004). Hence the ability to convert cytosine to uracil by deamination was established early in the eukaryote evolution and was then deployed repeatedly to serve specific needs in the various emerging taxa. No homologus protein has been found in the agnathan lymphocyte-like cell transcriptome or the Ciona genome, so these subfamilies of deaminating enzymes may repre- sent a gnathostome innovation. Some gnathostome species possess only one of the three AID functions, which suggests that they may have been acquired sequentially in gnathostome evolution. The antigen receptor diversification triggered by AID probably arose earlier in evolution than the RAG-mediated repertoire generation (Neuberger, 2008). Quite recently, a new role of AID in active DNA demethylation and reprogramming towards pluripotency in mammalian somatic cells has been discovered (Bhutani et al., 2010).

\section{CYTOKINE EVOLUTION}

The innate and adaptive immune systems do not operate independently of each other. Any interaction between receptors on macrophages and microbial components generates growth factor-like molecules, the cytokines that stimulate and direct the adaptive immune response. Below, only a general overview considering cytokine evolution is presented based on the reviews by Krause and Pestka (2005) and Huising et al., (2006). It is generally believed that our adaptive immune system evolved from a novel mechanism of self versus non-self recognition by virtue of discrimination of peptide sequence rather than pathogen-specific sugars or foreign lipids) to allow an effective way to eliminate viruses and virus-infected cells from an organism. In the Ciona genome no homologues of receptors employed by the adaptive immune system have been identified, but distant homologues of type I interferon receptors are present. According to Krause and Pestka (2005), IFNs and IFN receptors evolved during the chordate evolution but prior to the origin of vertebrates. Proteins involved in antiviral activity diverged before those involved in adaptive immunity. Genes encoding IFNs and IFN receptors duplicated multiple times during chordate evolution. The types I and II interferon (IFN $\gamma$ ) and IL-28-like proteins evolved as duplications from a primordial antiviral cytokine to improve or expand the innate response to viral and microbial infection. IL-10-like cytokines were derived from an IFN species as well. This suggests that many types of antiviral cytokines (interferon and interferon-like molecules) developed from the original "antiviral cytokine", and numerous cytokines evolved to assist the emerging adaptive immune system.

Many mammalian helical cytokines have orthologues in fishes; presumably, these cytokines emerged well before the divergence of tetrapods. Then, this cytokine family experienced gene duplication (IL-11, IL-12p40) and somatolactin became specific for the teleost fish lineage, whereas placental lactogens are restricted to the placental mammals. Pro-inflammatory cytokines (IL-1 $\beta$, TNF- $\alpha$ ) and anti-inflammatory ones (TGF- $\beta$ and IL-10) have been discovered in teleost fishes as well. Also IFN $\gamma$ and IL-18, which together with IL-12 drive the immune response towards Th1 (inflammatory response), are present in the teleost fishes. The only major group of cytokines for which not a single fish ortholog has been reported to date is the Th2 cluster (secreted in allergic diseases and helminthic infections). These cytokines are not found outside birds and mammals. This shows that Th1 and the cross-regulatory Th2 need not necesssarily have developed simultaneusly. Representatives of several classes of chemokines are also present in fish, although there is compelling evidence that the chemokine repertoires of fish and mammals differ extensively due to lineage-specific gene duplications. A common feature of all fish cytokines discovered to date is the low degree of primary sequence conservation they share with their mammalian orthologs. This relatively poor se- 
quence conservation prevents identification of non-mammalian orthologs of cytokine genes.

\section{CONCLUSIONS}

In this review the thesis is supported that many defense mechanisms generally believed to be specific to the immunity systems of advanced metazoans have been inherited from unicellular eukaryotic ancestors. Phagocytosis, used as a tool of immunity by specialized cells of invertebrates and vertebrates, serves for both food acquisition and defense in amoebae. Signalling, used in many cell pathways of the metazoans against foreign cells, is based on the TIR domain, which is indispensable for protists. Mammalian lysins are related to lytic factors secreted by amoebae. The immunity of sponges, nowadays the simplest multicellular organisms, is based on the same proteins or domains as that of higher organisms. Sponge molecules involved in self/non-self recognition, sensing of pathogens, cellular signalling and transport are homologous to those of higher animals.

A great body of such proteins survived during metazoan evolution until the origin of vertebrates. Thioester-containing $\alpha_{2}$-macroglobulin and C3 subfamilies, as well as I type and $V$ type domains of immunoglobulin family occur in the cnidarians. Although many mechanisms of immunity are common for invertebrates and vertebrates (phagocytosis, cytotoxicity, lectins, proteinases), others are only used in invertebrates (haemolymph clotting system, melanization) although the general plan on which they operate is realized in vertebrates as well. Some of those molecules, for instance Toll-like receptors, complement components or catalytic subunit of the phagocyte NADPH oxidase were lost in various animal groups.

The antibody-based immunity did not arise instantaneously. Individual components of this mechanism existed much earlier and only had to be adapted to a new function. Molecules assisting the synthesis of MHC class I proteins: calnexin, calreticulin, glucose-regulated protein of $78 \mathrm{kDa}$, and others are examples. Another group of proteins were modified after dupliction of their encoding genes. The modification adjusted the molecules to the requirements of the antibody-based immunity. Activation induced deaminase and three pairs of proteasome subunits of $\beta$ type are examples of this process. Duplications of the common ancestor of each gene pair encoding the $\beta$ subunits took place within the gnathostomes. But there is also a group of molecules that did not exist prior to the appearence of antibody-based immunity. It includes the MHC molecules, TCRs, and BCRs, all of fundamental importance for the antibody-based immunity. The MHCs presumably originated by shuffling of gene segments at the genomic level, which resulted in assembling together different domains or modifying preexisting ones. Probably also the new design of the peptide-binding domain (PBD) arose in such a way.

It can be concluded that the immunity of mammals is a result of sequential introduction of immunity mechanisms operating at various stages in the evolution, from the earliest unicellular eukaryotes through worm-like metazoans, fishes, and amphibian to reptile grade tetrapods. All the time those mechanisms were enriched with evolutionary innovations as a result of the Darwinian selection of spontaneously generated genetic variability. Also the role of gene duplication and exon shuffling in the creation of the most effective ways of fighting viruses, bacteria, and parasites cannot be overestimated.

\section{Acknowledgements}

I am very greateful to Jerzy Dzik (Institute of Paleobiology PAS and Faculty of Biology, University of Warsaw) for discussing evolutionary aspects of this paper and to Jan Fronk (Faculty of Biology, University of Warsaw) for constructive criticism and many helpful suggestions how to improve the manuscript, both in respect to its merits and language.

\section{REFERENCES}

Abi-Rached L, McDermott MF, Pontarotti P (1999) The MHC big bang. Immunol Rev 167: 33-44.

Agrawal A, Eastman QM, Schatz DG (1998) Transposition mediated by RAG1 and RAG2 and its implications for the evolution of the immune system. Nature 394: 744-751.

Akira K, Takahashi M, Matsushita M, EndoY, Nakata M. Mizuochi T. Fujita T (2001) Cloning and characterization of novel ficolins from the solitary urochordate. Halocynthia roretri. J Biol Chem 276: 1995919965.

Akira S, Uematsu S, Takeuchi O (2006) Pathogen recognition and innate immunity. Cell 124: 783-801.

Alder MN, Rogozin IB, Iyer LM, Glazko GV, Cooper MD, Pancer Z (2005) Diversity and function of adaptive immune receptors in a jawless vertebrate. Science 310: 1970-1973.

Allen PG, Dawidowicz EA (1990) Phagocytosis in Acanthamoeba: I. A mannose receptor is responsible for the binding and phagocytosis of yeast. J Cell Physiol 145: 508-513.

Amara U, Rittirsch D, Flierl M, Bruckner U, Klos A, Gebhard F, Lambris JD, Huber-Lang M (2008) Interaction between the coagulation and complement system. Adv Exp Med Biol 632: 71-79.

Ambach A, Bonnekoh B, Nguyen M, Schön MP, Gollnick H (2004) Imiquimod, a Toll-like receptor-7 agonist, induces perforin in cytotoxic T lymphocytes in vitro. Mol Immunol 40: 1307-1314.

Ariki S, Takahara S, Shibata T, Fukuoka T, Ozaki A, Endo Y, Fujita T, Koshiba T, Kawabata S (2008) Factor C acts as a lipopolysaccharide-responsive C3 convertase in horseshoe crab complement activation. J Immunol 181: 7994-8001.

Armstrong PB (2006) Proteases and protease inhibitors: a balance of activities in host-pathogen interaction. Immunobiology 211: 263-281.

Artavanis-Tsakonas K, Love JC, Ploegh HL, Vyas JM (2006) Recruitment of CD63 to Cryptococcus neoformans phagosomes requires acidification. Proc Natl Acad Sci USA 103: 15945-15950.

Ayala FJ, Rzhetsky A, Ayala FJ (1998) Origin of the metazoan phyla: molecular clocks confirm paleontological estimates. Proc Natl Acad Sci USA 95: 606-611.

Azumi K, De Santis R, De Tomaso A, Rigoutsos I, Yoshizaki F, Pinto MR, Marino R, Shida K, Ikeda I, Ikeda M, Arai M, Inoue Y, Shimizu T, Satoh N, Rokhsar DS, Du Pasquier L, Kasahara M, Satake M. Nonaka M (2003) Genomic analysis of immunity in a Urochordate and the emergence of the vertebrate immune system: 'waiting for Godot'. Immunogenetics 55: 570-581.

Babior BM (1999) NADPH oxidase: an update. Blood 93: 1464-1476.

Barwig B (1985) Isolation and characterization of plasma coagulogen of the cockroach Leucophaea maderae (Blattaria). J Comp Physiol (B) 155: $135-143$.

Beale RC, Petersen-Mahrt SK, Watt IN, Harris RS, Rada C, Neuberger MS (2004) Comparison of the differential context-dependence of DNA deamination by APOBEC enzymes: correlation with mutation spectra in vivo. I Mol Biol 337: 585-596.

Beck G, O'Brien RF, Habicht GS, Stillman DL, Cooper EL, Raftos DA (1993) Invertebrate cytokines III: Invertebrate interleukin-1-like molecules stimulate phagocytosis by tunicate and echinoderm cells. Cell Immunol 146: 284-299.

Beschin A, Bilej M, Torreele E, De Baetselier P (2001) On the existence of cytokines in invertebrates. Cell Mol Life Sci 58: 801-814.

Beutler B, Rehli M (2002) Evolution of the TIR, tolls and TLRs: functional inferences from computational biology. Curr Top Microbiol Immunol 270: 1-21.

Bhutani N, Brady JJ, Damian M, Sacco A, Corbel SY, Blau HM (2010) Reprogramming towards pluripotency requires AID-dependent DNA demethylation. Nature 463: 1042-1047.

Blandin S, Levashina EA (2004) Thioester-containing proteins and insect immunity. Mol Immunol 40: 903-908.

Blumbach B, Pancer Z, Diehl-Seifert B, Steffen R, Münkner J, Müller I, Müller WE (1998) The putative sponge aggregation receptor: isolation and characterization of a molecule composed of scavenger receptor cysteine-rich domains and short consensus repeats. I Cell Sci 111: 2635-2644.

Blumbach B, Diehl-Seifert B, Seack J, Steffen R, Müller IM, Müller WEG (1999) Cloning and expression of novel receptors belonging 
to the immunoglobulin superfamily from the marine sponge Geodia cydonium. Immunogenetics 49: 751-763.

Böhm M, Schröder HC, Müller IM, Müller WE, Gamulin V (2000) The mitogen-activated protein kinase p38 pathway is conserved in metazoans: cloning and activation of p38 of the SAPK2 subfamily from the sponge Suberites domuncula. Biol Cell 92: 95-104.

Borth W (1992) Alpha 2-macroglobulin, a multifunctional binding protein with targeting characteristics. FASEB J 6: 3345-3353

Bouige P, Laurent D, Piloyan L, Dassa E (2002) Phylogenetic and functional classification of ATP-binding cassette (ABC) systems. Curr Protein Pept Sci 3: 541-559.

Brehélin M (1979) Hemolymph coagulation in Locusta migratoria: evidence for a functional equivalent of fibrinogen. Comp Biochem Physiol (B) 62: 329-334.

Brogden KA (2005) Antimicrobial peptides: pore formers or metabolic inhibitors in bacteria? Nat Rev Microbiol 3: 238-250.

Buljan M, Bateman A 2009) The evolution of protein domain families. Biochem Soc Trans 37: 751-755.

Cannon JP, Haire RN, Litman GW (2002) Identification of diversified genes that contain immunoglobulin-like variable regions in a protochordate. Nat Immunol 3: 1200-1207.

Cannon JP, Haire RN, Rast JP, Litman GW (2004) The phylogenetic origins of the antigen-binding receptors and somatic diversification mechanisms. Immunol Rev 200: 12-22.

Cardelli J (2001) Phagocytosis and macropinocytosis in Dictyostelium: phosphoinositide-based processes, biochemically distinct. Traffic 2: 311-320.

Cerenius L, Söderhäll K (2004) The prophenoloxidase-activating system in invertebrates. Immunol Rev 198: 116-126.

Chen G, Zhuchenko O, Kuspa A (2007) Immune-like phagocyte activity in the social amoeba. Science 317: 678-681.

Cho WL, Liu HF, Lee CH, Kuo CC, Chang TY, Liu CT, Chen CC (1998) Molecular cloning, characterization and tissue expression of prophenoloxidase cDNA from the mosquito Armigeres subalbatus innoculated with Dirofilaria immitis microfilariae. Insect Mol Biol 7: $31-40$.

Cooper EL, Mansour MH, Negm HI (1996) Marine invertebrate immunodefense responses: Molecular and cellular approaches in tunicates Ann Rev Fish Dis 6: 133-149.

Cox RL, Mariano T, Heck DE, Laskin JD, Stegeman JJ (2001) Nitric oxide synthase sequences in the marine fish Stenotomus chrysops and the sea urchin Arbacia punctulata, and phylogenetic analysis of nitric oxide synthase calmodulin-binding domains. Comp Biochem Physiol B Biochem Mol Biol 130: 479-491.

Daffre S, Kylsten P, Samakovlis C, Hultmark D (1994) The lysozyme locus in Drosophila melanogaster: an expanded gene family adapted for expression in the digestive tract. Mol Gen Genet 242: 152-162.

Danchin EG, Abi-Rached L, Gilles A, Pontarotti P (2003) Conservation of the MHC-like region throughout evolution. Immunogenetics 55: $141-148$.

Dangott LJ, Jordan JE, Bellet RA, Garbers DL (1989) Cloning of the mRNA for the protein that crosslinks to the egg peptide speract. Proc Natl Acad Sci USA 86: 2128-2132.

Danilova N (2006) The evolution of immune mechanisms. J Exp Zool 306B: 496-520.

Davies B, Chattings LS, Edwards SW (1991) Superoxide generation during phagocytosis by Acanthamoeba castellanii: similarities to the respiratory burst of immune phagocytes. J Gen Microbiol 137: 705-710.

De Tomaso AW, Nyholm SV, Palmeri KJ, Ishizuka KJ, Ludington WB, Mitchel K, Weissman IL (2005) Isolation and characterization of a protochordate histocompatibility locus. Nature 438: 454-459.

Decker H, Schweikardt T, Nillius D, Salzbrunn U, Jaenicke E, Tuczek F (2007) Similar enzyme activation and catalysis in hemocyanins and tyrosinases. Gene 398: 183-191.

Dijkstra JM, Kiryu I, Kollner B, Yoshiura Y, Ototake M (2003) MHC class II invariant chain homologues in rainbow trout (Oncorbynchus mykiss). Fish Shellfish Immunol 15: 91-105.

Dodd RB, Drickamer K (2001) Lectin-like proteins in model organisms: implications for evolution of carbohydrate-binding activity. Glycobiology 11: 71R-79R.

Dodds AW, Law SK (1998) The phylogeny and evolution of the thioester bond-containing proteins C3, C4 and alpha 2-macroglobulin. Immunol Rev 166: 15-26.

Dodds AW, Smith SL, Levine RP, Willis AC (1998) Isolation and initial characterisation of complement components C3 and C4 of the nurse shark and the channel catfish. Dev Comp Immunol 22: 207-216.

Doolittle RF, Riley M (1990) The amino-terminal sequence of lobster fibrinogen reveals common ancestry with vitellogenins. Biochem Biophys Res Commun 167: 16-19.

dos Remedios NJ, Ramsland PA, Hook JW, Raison RL (1999) Identification of a homologue of CD59 in a cyclostome: implications for the evolutionary development of the complement system. Dev Comp Immunol 23: 1-14.

Dreyfus DH (2009) Paleo-immunology: evidence consistent with insertion of a primordial herpes virus-like element in the origins of acquired immunity. PLoS One 4: e5778.
Du Pasquier L, Zucchetti I, De Santis R (2004) Immunoglobulin superfamily receptors in protochordates: before RAG time. Immunol Rev 198: 233-248.

Dzik JM (2006) Molecules released by helminth parasites involved in host colonization. Acta Biochim Pol 53: 33-64.

Dzik JM, Zieliński Z, Gołos B, Wałajtys-Rode E (2006) Trichinella spiralis infection affects $\mathrm{p} 47$ (phox) protein expression in guinea-pig alveolar macrophages. Exp Parasitol 112: 158-163.

Dzik JM, Zieliński Z, Cieśla J, Wałajtys-Rode E (2010) Trichinella spiralis infection enhances protein kinase $C$ phosphorylation in guinea-pig alveolar macrophages. Parasite Immunol 32: 209-220.

Elphick MR, Williams L, O'Shea M (1996) New features of the locust optic lobe: evidence of a role for nitric oxide in insect vision. $J$ Exp Biol 199: 2395-2407.

Endo Y, Takahashi M, Fujita T (2006) Lectin complement system and pattern recognition. Immunobiology 211: 283-293.

Fautin DG, Mariscal RN (1991) Cnidaria: Anthozoa. Harrison FW, Westfall JA, eds. Microscopic Anatomy of Invertebrates, Placozoa, Porifera, Cnidaria, and Ctenophora, vol 2, pp 267-358. Wiley-Liss, Inc, New York and other cities.

Fernàndez-Busquets X, Burger MM (1997) The main protein of the aggregation factor responsible for species-specific cell adhesion in the marine sponge Microciona prolifera is highly polymorphic. J Biol Chem 272: 27839-27847.

Flajnik MF, Kasahara M (2001) Comparative genomics of the MHC: glimpses into the evolution of the adaptive immune system. Immunity 15: 351-362.

Fujii T, Nakamura T, Sekizawa A, Tomonaga S (1992) Isolation and characterization of a protein from hagfish serum that is homologous to the third component of the mammalian complement system. J Immunol 148: 117-123.

Fujito NT, Sugimoto S, Nonaka M (2010) Evolution of thioestercontaining proteins revealed by cloning and characterization of their genes from a cnidarian sea anemone, Haliplanella lineate. Dev Comp Immunol 34: 775-784.

Fuller GM, Doolittle RF (1971) Studies of invertebrate fibrinogen. II. Transformation of lobster fibrinogen into fibrin. Biochemistry 10: 1311-1315.

Gan X, Ma Z, Deng N, Wang J, Ding J, Li L (2004) Involvement of the C-terminal proline-rich motif of $\mathrm{G}$ protein-coupled receptor kinases in recognition of activated rhodopsin. J Biol Chem 279: 49741-49746.

Garcia-Garcia E, Prado-Alvarez M, Novoa B, Figueras A, Rosales C (2008) Immune responses of mussel hemocyte subpopulations are differentially regulated by enzymes of the PI-3K, PKC, and ERK kinase families. Dev Comp Immunol 32: 637-653.

Gauthier M, Degnan BM (2008) The transcription factor NF- $x$ B in the demosponge Amphimedon queenslandica: insights on the evolutionary origin of the Rel homology domain. Dev Genes Evol 218: 23-32.

Giovine M, Pozzolini M, Favre A, Bavestrello G, Cerrano C, Ottaviani F, Chiarantini L, Cerasi A, Cangiotti M, Zocchi E, Scarfi S, Sarà M, Benatti U (2001) Heat stress-activated, calcium-dependent nitric oxide synthase in sponges. Nitric Oxide 5: 427-431.

Gottar M, Gobert V, Michel T, Belvin M, Duyk G, Hoffmann JA, Ferrandon D, Royet J (2002) The Drosophila immune response against Gram-negative bacteria is mediated by a peptidoglycan recognition protein. Nature 416: 640-644.

Guo P, Hirano M, Herrin BR, Li J, Yu C, Sadlonova A, Cooper MD (2009) Dual nature of the adaptive immune system in lampreys. $\mathrm{Na}$ ture 459: 796-801.

Ha EM, Lee KA, Park SH, Kim SH, Nam HJ, Lee HY, Kang D, Lee WJ (2009) Regulation of DUOX by the Galphaq-phospholipase C $\beta$ $\mathrm{Ca}^{2+}$ pathway in Drosophila gut immunity. Dev Cell 16: 386-397.

Halaby DM, Mornon JP (1998) The immunoglobulin superfamily: an insight on its tissular, species, and functional diversity. $J$ Mol Evol 46: 389-400.

Hancock RE, Brown KL, Mookherjee N (2006) Host defence peptides from invertebrates - emerging antimicrobial strategies. Immunobiology 211: $315-322$.

Hanley PJ, Hook JW, Raftos DA, Gooley AA, Trent R, Raison RL (1992) Hagfish humoral defense protein exhibits structural and functional homology with mammalian complement components. Proc Natl Acad Sci USA 89: 7910-7914.

Hartenstein V (2006) Blood cells and blood cell development in the animal kingdom. Annu Rev Cell Dev Biol 22: 677-712.

Hemmrich G, Miller DJ, Bosch TC (2007) The evolution of immunity: a low-life perspective. Trends Immunol 28: 449-454.

Hiltbold EM, Roche PA (2002) Trafficking of MHC class II molecules in the late secretory pathway. Curr Opin Immunol 14: 30-35.

Hirabayashi J, Kusunoki T, Kasai K-I (1991) Complete primary structure of a galactose-specific lectin from the venom of the rattlesnake Crotalus atrox. J Biol Chem 266: 2320-2326.

Hirabayashi J, Satoh M, Kasai K-I (1992) Evidence that Caenorhabditis elegans $32-\mathrm{kDa} \beta$-galactoside-binding protein is homologous to vertebrate $\beta$-galactoside-binding lectins. J Biol Chem 267: 15485-15490. 
Hoffmann JA (2003) The immune response of Drosophila. Nature 426: 33-38.

Hogan BL (1996) Bone morphogenetic proteins in development. Curr Opin Genet Dev 4: 432-438.

Honjo T, Muramatsu M, Fagarasan S (2004) AID: how does it aid antibody diversity? Immunity 20: 659-668.

Hood L, Kronenberg M, Hunkapiller T (1985) T-cell antigen receptors and the immunoglobulin supergene family. Cell 40: 225-229.

Hourcade D, Holers VM, Atkinson JP (1989) The regulators of complement activation (RCA) gene cluster. Adv Immunol 45: 381-416.

Huang S, Yuan S, Guo L, Yu Y, Li J, Wu T, Liu T, Yang M, Wu K, Liu H, Ge J, Yu Y, Huang H, Dong M, Yu C, Chen S, Xu A (2008) Genomic analysis of the immune gene repertoire of amphioxus reveals extraordinary innate complexity and diversity. Genome Res 18: 1112-1126.

Hughes AL (1998) Protein phylogenies provide evidence of a radical discontinuity between arthropod and vertebrate immune systems. Immunogenetics 47: 283-296.

Hughes AL (1999) Genomic catastrophism and the origin of vertebrate immunity. Arch Immunol Ther Exp (Warsz) 47: 347-353.

Hughes AL, Nei M (1993) Evolutionary relationships of the classes of major histocompatibility complex genes. Immunogenetics 37: 337-346.

Huising MO, Kruiswijk CP, Flik G (2006) Phylogeny and evolution of class-I helical cytokines. J Endocrinol 189: 1-25.

Humphreys T, Reinherz EL (1994) Invertebrate immune recognition, natural immunity and the evolution of positive selection. Immunol Today 15: 316-320.

Ikawa M, Wada I, Kominami K, Watanabe D, Toshimori K, Nishimune Y, Okabe M (1997) The putative chaperone calmegin is required for sperm fertility Nature 387: 607-611.

Inamori K, Ariki S, Kawabata S (2004) A Toll-like receptor in horseshoe crabs. Immunol Rev 198: 106-115.

Inoue Y, Ogasawara M, Moroi T, Satake M, Azumi K, Moritomo T, Nakanishi T (2005) Characteristics of NADPH oxidase genes (Nox2, p22, p47, and p67) and Nox4 gene expressed in blood cells of juvenile Ciona intestinalis. Immunogenetics 57: 520-534.

Irazoqui JE, Urbach JM, Ausubel FM (2010) Evolution of host innate defence: insights from Caenorhabditis elegans and primitive invertebrates. Nat Rev Immunol 10: 47-58.

Irving P, Ubeda JM, Doucet D, Troxler L, Lagueux M, Zachary D, Hoffmann JA, Hetru C, Meister M (2005) New insights into Drosophila larval haemocyte functions through genome-wide analysis. Cell Microbiol 7: 335-350.

Iwanga S, Kawabata S (1998) Evolution and phylogeny of defense molecules associated with innate immunity in horseshoe crab. Front Biosci 3: D973-D984.

Jensen JA, Festa E, Smith DS, Cayer M (1981) The complement system of the nurse shark: hemolytic and comparative characteristics. Science 214: 566-569.

Ji X, Azumi K, Sasaki M, Nonaka M (1997) Ancient origin of the complement lectin pathway revealed by molecular cloning of mannan binding protein-associated serine protease from a urochordate, the Japanese urochordate, Halocynthia roretzi. Proc Natl Acad Sci USA 94: 6340-6345.

Kanzok SM, Hoa NT, Bonizzoni M, Luna C, Huang Y, Malacrida AR, Zheng L (2004) Origin of Toll-like receptor-mediated innate immunity. J Mol Evol 58: 442-448.

Kapitonov VV, Jurka J (2005) RAG1 core and V(D)J recombination signal sequences were derived from Transib transposons. PloS Biol 3: e181.

Kasahara M, Flajnik MF, Ishibashi T, Natori T (1995) Evolution of the major histocompatibility complex: a current overview. Transpl Immunol 3: 1-20.

Kasahara M, Nakaya J, Satta Y, Takahata N (1997) Chromosomal duplication and the emergence of the adaptive immune system. Trends Genet 13: 90-92.

Kasahara M, Suzuki T, Pasquier LD (2004) On the origins of the adaptive immune system: novel insights from invertebrates and cold-blooded vertebrates. Trends Immunol 25: 105-111.

Kaur H, Jaso-Friedmann L, Evans DL (2003) Identification of a scavenger receptor homologue on nonspecific cytotoxic cells and evidence for binding to oligodeoxyguanosine. Fish Shellfish Immunol 15: 169-181.

Kauschke E, Komiyama K, Moro I, Eue I, König S, Cooper EL (2001) Evidence for perforin-like activity associated with earthworm leukocytes. Zoology (Jena) 104: 13-24.

Kawahara T, Lambeth JD (2007) Molecular evolution of Phox-related regulatory subunits for NADPH oxidase enzymes. BMC Evol Biol 7: 178.

Kenjo A, Takahashi M, Matsushita M, Endo Y, Nakata M, Mizuochi T, Fujita T (2001) Cloning and characterization of novel ficolins from the solitary ascidian, Halocynthia roretri. J Biol Chem 276: 19959-19965.

Khalturin K, Bosch TC (2007) Self/non-self discrimination at the basis of chordate evolution: limits on molecular conservation. Curr Opin Immunol 19: 4-9.
Khalturin K, Becker M, Rinkevich B, Bosch TC (2003) Urochordates and the origin of natural killer cells: identification of a CD94/NKRP1-related receptor in blood cells of Botryllus. Proc Natl Acad Sci USA 100: 622-627.

Kimura Y, Inoue N, Fukui A, Oshiumi H, Matsumoto M, Nonaka M, Kuratani S, Fujita T, Nonaka M, Seya T (2004) A short consensus repeat-containing complement regulatory protein of lamprey that participates in cleavage of lamprey complement 3. J Immunol 173: 1118-1128.

Kimura A, Sakaguchi E, Nonaka M (2009) Multi-component complement system of Cnidaria: C3, Bf, and MASP genes expressed in the endodermal tissues of a sea anemone. Nematostella vectensis. Immunobiology 214: 165-178.

Kindt TJ, Goldsby RA, Osborne BA (2007) Kuby Immunology. Sixth edn. W.H. Freeman and Company, New York.

King N, Hittinger CT, Carroll SB (2003) Evolution of key cell signaling and adhesion protein families predates animal origins. Science 301: 361-363.

Kingsley DM (1994) The TGF- $\beta$ superfamily: new members, new receptors, and new genetic tests of function in different organisms. Genes Dev 8:133-146.

Klein J (1986) natural bistory of the major histocompatibility complex. Wiley Interscience. New York.

Klein J (2006) The grapes of incompatibility. Dev Cell 10: 2-4.

Klein J, O'hUigin C (1993) Composite origin of major histocompatibility complex genes. Curr Opin Genet Dev 3: 923-930.

Klein J, Nikolaidis N (2005) The descent of the antibody-based immune system by gradual evolution. Proc Natl Acad Sci USA 102: 169-174.

Kopacek P, Hall KM, Söderhäll K (1993) Characterization of a clotting protein, isolated from plasma of the freshwater crayfish Pacifastacus leniusculus. Eur I Biochem 213: 591-597.

Krarup A, Wallis R, Presanis JS, Gál P, Sim RB (2007) Simultaneous activation of complement and coagulation by MBL-associated serine protease 2. PLoS One 2: e623.

Krasko A, Gamulin V, Seack J, Steffen R, Schröder HC, Müller WEG (1997) Cathepsin, a major protease of the marine sponge Geodia cydonium: purification of the enzyme and molecular cloning of cDNA Mol Marine Biol Biotechnol 6: 296-307.

Krause CD, Pestka S (2005) Evolution of the Class 2 cytokines and receptors, and discovery of new friends and relatives. Pharmacol Ther 106: $299-346$

Krem MM, Di Cera E (2002) Evolution of enzyme cascades from embryonic development to blood coagulation. Trends Biochem Sci 27: 67-74.

Krushkal J, Kemper C, Gigli I (1998) Ancient origin of human complement factor H. J Mol Evol 47: 625-630.

Kusumoto H, Hirosawa S, Salier JP, Hagen FS, Kurachi K (1988) Human genes for complement components $\mathrm{C} 1 \mathrm{r}$ and $\mathrm{C} 1 \mathrm{~s}$ in a close tail-to-tail arrangement. Proc Natl Acad Sci USA 85: 7307-7311.

Laird DJ, De Tomaso AW, Weissman IL (2005) Stem cells are units of natural selection in a colonial ascidian. Cell 123: 1351-1360.

Lardy B, Bof M, Aubry L, Paclet MH, Morel F, Satre M, Klein G (2005) NADPH oxidase homologs are required for normal cell differentiation and morphogenesis in Dictyostelium discoideum. Biochim Biophys Acta 1744: 199-212.

Lazzaro BP (2005) Elevated polymorphism and divergence in the class C scavenger receptors of Drosophila melanogaster and D. simulans. Genetics 169: 2023-2034.

Lee PH, Goetz FW (1998) Characterization of a novel cDNA obtained through differential-display PCR of phorbol ester-stimulated ovarian tissue from the brook trout (Salvelinus fontinalis). Mol Reprod Dev 49: 112-118.

Leippe M (1995) Ancient weapons: NK-lysin, is a mammalian homolog to pore-forming peptides of a protozoan parasite. Cell 83: 17-18.

Leippe M (1999) Antimicrobial and cytolytic peptides of ameboid protozoa - effector molecules of primitive phagocytes. Dev Comp Immunol 23: 267-279.

Leippe M, Andrä J, Nickel R, Tannich E, Müller-Eberhard HJ (1994) Amoebapores, a family of membranolytic peptides from cytoplasmic granules of Entamoeba histolytica: isolation, primary structure, and pore formation in bacterial cytoplasmic membranes. Mol Microbiol 14: 895-904.

Letterio JJ, Roberts AB (1998) Regulation of immune responses by TGF- $\beta$. Annu Rev Immunol 16: 137-161.

Levashina EA, Moita LF, Blandin S, Vriend G, Lagueux M, Kafatos FC (2001) Conserved role of a complement-like protein in phagocytosis revealed by dsRNA knockout in culture cells of the mosquito, Anopheles gambiae. Cell 104: 709-718.

Li X, Namikawa-Yamada C, Nakanishi M, Sasaki M, Nonaka M (2000) Molecular cloning of complement factor B from a solidary ascidian: unique combination of domains and implicating ancient exon shufflings. Immunopharmacology 49: 43.

Little KD, Hemler ME, Stipp CS (2004) Dynamic regulation of a GPCR-tetraspanin-G protein complex on intacT-cells: central role 
of CD81 in facilitating GPR56-Galpha q/11 association. Mol Biol Cell 15: 2375-2387.

Lucas R, Magez S, De Leys R, Fransen L, Scheerlinck JP, Rampelberg M, Sablon E, De Baetselier P (1994) Mapping the lectin-like activity of tumor necrosis factor. Science 263: 814-817.

Luckhart S, Rosenberg R (1999) Gene structure and polymorphism of an invertebrate nitric oxide synthase gene. Gene 232: 25-34.

Luo C, Zheng L (2000) Independent evolution of Toll and related genes in insects and mammals. Immunogenetics 1: 92-98.

Mah SA, Moy GW, Swanson WJ, Vacquier VD (2004) A perforin-like protein from a marine mollusk. Biochem Biophys Res Commun 316: 468-475.

Mangel A, Leitão JM, Batel R, Zimmermann H, Müller WE, Schröder HC (1992) Purification and characterization of a pore-forming protein from the marine sponge Tethya lyncurium. Eur J Biochem 210: 499-507.

Marmaras VJ, Charalambidis ND, Zervas CG (1996) Immune response in insects: the role of phenoloxidase in defense reactions in relation to melanization and sclerotization. Arch Insect Biochem Physiol 31: 119-133.

Matsushita M, Takahashi M, Thiel S, Jensenius JC, Fujita T (1998) Distinct proteolytic activities of MASP-1 and MASP-2. Mol Immunol 35: 349-349.

Matsushita M, Matsushita A, Endo Y, Nakata M, Kojima N, Mizuochi T, Fujita T (2004) Origin of the classical complement pathway: Lamprey orthologue of mammalian C1q acts as a lectin. Proc Natl Acad Sci USA 101: 10127-10131.

Mayer WE, Tichy H (1995) A cDNA clone from the sea lamprey Petromyzon marinus coding for a scavenger receptor Cys-rich (SRCR) domain protein. Gene 164: 267-271.

Meister M, Lagueux M (2003) Drosophila blood cells. Cell Microbiol 5: $573-580$.

Miller MM, Wang C, Parisini E, Coletta RD, Goto RM, Lee SY, Barral DC, Townes M, Roura-Mir C, Ford HL, Brenner MB, Dascher CC (2005) Characterization of two avian MHC-like genes reveals an ancient origin of the CD1 family Proc Natl Acad Sci USA 102: 8674-8679.

Miller DJ, Hemmrich G, Ball EE, Hayward DC, Khalturin K, Funayama N, Agata K, Bosch TC (2007) The innate immune repertoire in cnidaria - ancestral complexity and stochastic gene loss. Genome Biol 8: 1-13.

Minnick MF, Rupp RA, Spence KD (1986) A bacterial-induced lectin which triggers hemocyte coagulation in Manduca sexta. Biochem Biophys Res Commun 137: 729-735.

Mondragon-Palomino M, Pinero D, Nicholson-Weller A, Laclette JP (1999) Phylogenetic analysis of the homologous proteins of the terminal complement complex supports the emergence of C6 and C7 followed by C8 and C9. J Mol Evol 49: 282-289.

Morgan BP (1999) Regulation of the complement membrane attack pathway. Crit Rev Immunol 19: 173-198.

Moscona AA (1968) Cell aggregation: properties of specific cell-ligands and their role in the formation of multicellular systems. Dev Biol 18: $250-277$.

Müller WE, Blumbach B, Müller IM (1999a) Evolution of the innate and adaptive immune systems: relationships between potential immune molecules in the lowest metazoan phylum (Porifera) and those in vertebrates. Transplantation 68: 1215-1227.

Müller WE, Koziol C, Müller IM, Wiens M (1999b) Towards an understanding of the molecular basis of immune responses in sponges: the marine demosponge Geodia cydonium as a model. Microsc Res Tech 44: 219-236.

Munford RS, Sheppard PO, O’Hara PJ (1995) Saposin-like proteins (SAPLIP) carry out diverse functions on a common backbone structure. J Lipid Res 36: 1653-1663.

Muta T, Iwanaga S (1996) The role of hemolymph coagulation in innate immunity. Curr Opin Immunol 8: 41-47.

Muta T, Miyata T, Misumi Y, Tokunaga F, Nakamura T, Toh Y, Ikehara Y, Iwanaga S (1991) Limulus factor C. An endotoxin-sensitive serine protease zymogen with a mosaic structure of complementlike, epidermal growth factor-like, and lectin-like domains. J Biol Chem 266: 6554-6561.

Muta T, Seki N, Takaki Y, Hashimoto R, Oda T, Iwanaga A, Tokunaga F, Iwanaga S (1995) Purified horseshoe crab factor G. Reconstitution and characterization of the $(1 \rightarrow 3)-\beta$-D-glucan-sensitive serine protease cascade. J Biol Chem 270: 892-897.

Nagai T, Kawabata S (2000) A link between blood coagulation and prophenol oxidase activation in arthropod host defense. $J$ Biol Chem 275: 29264-29267.

Nakao M, Osaka K, Kato Y, Fujiki K, Yano T (2001) Molecular cloning of the complement $(\mathrm{C} 1 \mathrm{r} / \mathrm{C} 1 \mathrm{~s} / \mathrm{MASP} 2$-like serine proteases from the common carp (Cyprinus carpio). Immunogenetics 52: 255-263.

Nakao M, Hisamatsu S, Nakahara M, Kato Y, Smith SL, Yano T (2003a) Molecular cloning of the complement regulatory factor I isotypes from the common carp (Cyprinus carpio). Immunogenetics 54: 801-806.
Nakao M, Mutsuro J, Nakahara M, Kato Y, Yano T (2003b) Expansion of genes encoding complement components in bony fish: biological implications of the complement diversity. Dev Comp Immunol 27: 749-762.

Nappi AJ, Ottaviani E (2000) Cytotoxicity and cytotoxic molecules in invertebrates. Bioessays 22: 469-480.

Nappi AJ, Vass E, Frey F, Carton Y (1995) Superoxide anion generation in Drosophila during melanotic encapsulation of parasites. Eur J Cell Biol 68: 450-456.

Nappi AJ, Vass E, Frey F, Carton Y (2000) Nitric oxide involvement in Drosophila Immunity Nitric Oxide 4: 423-430.

Neuberger MS (2008) Antibody diversification by somatic mutation: from Burnet onwards. Immunol Cell Biol 86: 124-132.

Niedermann G, Grimm R, Geier E, Maurer M, Realini C, Gartmann C, Soll J, Omura S, Rechsteiner MC, Baumeister W, Eichmann K (1997) Potential immunocompetence of proteolytic fragments produced by proteasomes before evolution of the vertebrate immune system. J Exp Med 186: 209-220.

Nonaka M (2001) Evolution of the complement system. Curr Opin Immunol 13: 69-73.

Nonaka M, Takahashi M (1992) Complete complementary DNA sequence of the third component of complement of lamprey. Implication for the evolution of thioester containing proteins. I Immunol 148: 3290-3295.

Nonaka M, Miyazawa S (2002) Evolution of the initiating enzymes of the complement system. Genome Biol 3 Reviews 1001.

Nonaka M, Kimura A (2006) Genomic view of the evolution of the complement system. Immunogenetics 58: 701-713.

Nonaka M, Matsuda Y, Shiroishi T, Moriwaki K, Nonaka M, Natsuume-Sakai S (1993) Molecular cloning of the b subunit of mouse coagulation factor XIII and assignment of the gene to chromosome 1: close evolutionary relationship to complement factor H. Genomics 15: $535-542$.

Nonaka M, Takahashi M, Sasaki M (1994) Molecular cloning of a lamprey homologue of the mammalian MHC class III gene, complement factor B. I Immunol 152: 2263-2269.

Nonaka M, Azumi K, Ji X, Namikawa-Yamada C, Sasaki M, Saiga H,. Dodds AW, Sekine H, Homma MK, Matsushita M, Endo Y, Fujita $\mathrm{T}$ (1999) Opsonic complement component C3 in the solitary urochordate, Halocynthia roretzi. I Immunol 162: 387-391.

Nonaka M, Yamada-Namikawa C, Flajnik MF, Du Pasquier L (2000) Trans-species polymorphism of the major histocompatibility complex-encoded proteasome subunit LMP7 in an amphibian genus, Xenopus. Immunogenetics 51: 186-192.

Nosanchuk JD, Casadevall A (2003) The contribution of melanin to microbial pathogenesis. Cell Microbiol 5: 203-223.

Ohno S (1987) The ancestor of the adaptive immune system was the CAM system for organogenesis. Exp Clin Immunogenet 4: 181-192.

Osaki T, Kawabata S (2004) Structure and function of coagulogen, a clottable protein in horseshoe crabs. Cell Mol Life Sci 61: 1257-1265.

Ottaviani E, Franceschi C (1997) The invertebrate phagocytic immunocyte: clues to a common evolution of immune and neuroendocrine systems. Immunol Today 18: 169-174.

Pahler S, Blumbach B, Muller I, Muller EW (1998) Putative multiadhesive protein from the marine sponge Geodia cydonium: cloning of the cDNA encoding a fibronectin-, an SRCR-, and a complement control protein module. J Exp Zool 282: 332-343.

Pålsson-McDermott EM, O’Neill LA (2004) Signal transduction by the lipopolysaccharide receptor, Toll-like receptor-4. Immunology 113: $153-162$.

Palumbo A (2005) Nitric oxide in marine invertebrates: A comparative perspective. Comp Biochem Physiol (Part A) 142: 241-248.

Pancer Z (2000) Dynamic expression of multiple scavenger receptor cysteine-rich genes in coelomocytes of the purple sea urchin. Proc Natl Acad Sci USA 97: 13156-13161.

Pancer Z, Kruse M, Schäcke H, Scheffer U, Steffen R, Kovács P, Müller WE (1996a) Polymorphism in the immunoglobulin-like domains of the receptor tyrosine kinase from the sponge Geodia cydonium. Cell Adhes Commun 4: 327-339.

Pancer Z, Scheffer U, Müller I, Müller WEG (1996b) Cloning of sponge (Geodia cydonium) and tunicate (Botryllus schlosseri) proteasome subunit epsilon (PRCE): implications about the evolution of the vertebrate MHC-encoded homologue LMP7 (PRCC). Biochem Biophys Res Commun 228: 406-410.

Pancer Z, Münkner J, Müller I, Müller WEG (1997) A novel member of an ancient superfamily: sponge (Geodia cydonium, Porifera) putative protein that features scavenger receptor cysteine-rich repeats. Gene 193: $211-218$.

Pancer Z, Skorokhod A, Blumbach B, Müller WEG (1998) Multiple Ig-like featuring genes divergent within and among individuals of the marine sponge Geodia cydonium. Gene 207: 227-233.

Pancer Z, Amemiya CT, Ehrhardt GR, Ceitlin J, Gartland GL, Cooper MD (2004a) Somatic diversification of variable lymphocyte receptors in the agnathan sea lamprey. Nature 430: 174-180.

Pancer Z, Mayer WE, Klein J, Cooper MD (2004b) Prototypic T-cell receptor and CD4-like coreceptor are expressed by lymphocytes 
in the agnathan sea lamprey. Proc Natl Acad Sci USA 101: 1327313278.

Peiseret L, Mukhopadhyay S, Gordon S (2002) Scavenger receptors in innate immunity. Curr Opin Immunol 14: 123-128.

Peña SV, Hanson DA, Carr BA, Goralski TJ, Krensky AM (1997) Processing, subcellular localization, and function of 519 (granulysin), a human late T-cell activation molecule with homology to small, lytic, granule proteins. I Immunol 158: 2680-2688.

Penna G, Vulcano M, Sozzani S, Adorini L (2002) Differential migration behavior and chemokine production by myeloid and plasmacytoid dendritic cells. Hum Immunol 63: 1164-1171.

Pereira LS, Oliveira PL, Barja-Fidalgo C, Daffre S (2001) Production of reactive oxygen species by hemocytes from the cattle tick Boophilus microplus. Exp Parasitol 99: 66-72.

Perović-Ottstadt S, Adell T, Proksch P, Wiens M, Korzhev M, Gamulin V, Müller IM, Müller WE (2004) A $(1 \rightarrow 3)$ - $\beta$-D-glucan recognition protein from the sponge Suberites domuncula. Mediated activation of fibrinogen-like protein and epidermal growth factor gene expression. Eur J Biochem 271: 1924-1937.

Peskin AV, Labas YA, Tikhonov AN (1998) Superoxide radical production by sponges Sycon sp. FEBS Lett 434: 201-204.

Pfeifer, K, Haaseman M, Gamulin V, Bretting H, Fahrenholz F, Müller WEG (1993) S-Type lectins occur also in invertebrates: High conservation of the carbohydrate recognition domain in the lectin genes from the marine sponge Geodia cydonium. Glycobiology 3: 179-184.

Płonka PM, Grabacka M (2006) Melanin synthesis in microorganism - biotechnological and medical aspects. Acta Biochim Pol 53: $429-443$.

Podack ER, Olsen KJ, Lowrey DM, Lichtenheld M (1989) Structure and function of perforin. Curr Top Microbiol Immunol 140: 11-17.

Powis SJ, Deverson EV, Coadwell WJ, Ciruela A, Huskisson NS, Smith H, Butcher GW, Howard JC (1992) Effect of polymorphism of an MHC-linked transporter on the peptides assembled in a class I molecule. Nature 357: 211-215.

Prager EM (1996) Adaptive evolution of lysozyme: changes in amino acid sequence, regulation of expression and gene number. EXS 75: 323-345.

Pujol N, Link EM, Liu LX, Kurz CL, Alloing G, Tan MW, Ray KP, Solari R, Johnson CD, Ewbank JJ (2001) A reverse genetic analysis of components of the Toll signaling pathway in Caenorbabditis elegans. Curr Biol 11: 809-821.

Qiu L, Song L, Xu W, Ni D, Yu Y (2007) Molecular cloning and expression of a Toll receptor gene homologue from Zhikong Scallop, Chlamys farreri. Fish Shellfish Immunol 22: 451-466.

Raftos D (1996) Interactions of tunicate immunomodulatory proteins with mammalian cells. Immunol Cell Biol 74: 26-31.

Rast JP, Litman GW (1994) T-cell receptor gene homologs are present in the most primitive jawed vertebrates. Proc Natl Acad Sci USA 91: 9248-9252.

Rast JP, Smith LC, Loza-Coll M, Hibino T, Litman GW (2006) Genomic insights into the immune system of the sea urchin. Science 314: 952-956.

Rathjen JP, Chang JH, Staskawicz BJ, Michelmore RW (1999) Constitutively active Pto induces a Prf-dependent hypersensitive response in the absence of avrPto. EMBO J 18: 3232-3240.

Reid KBM, Day AJ (1989) Structure-function relationship of the complement components. Immunol Today 10: 177-180.

Resnick D, Pearson A, Krieger M (1994) The SRCR superfamily: a family reminiscent of the Ig superfamily. Trends Biochem Sci 19: 5-8.

Rhodes CP, Ratcliffe NA, Rowley AF (1982) Presence of coelomocytes in the primitive chordate amphioxus (Branchiostoma lanceolatum). Science 217: 263-265.

Ribeiro JM, Hazzard JM, Nussenzveig RH, Champagne DE, Walker FA (1993) Reversible binding of nitric oxide by a salivary heme protein from a bloodsucking insect. Science 260: 539-541.

Rivero A (2006) Nitric oxide: an antiparasitic molecule of invertebrates. Trends Parasitol 22: 219-224.

Ryan RO, van der Horst DJ (2000) Lipid transport biochemistry and its role in energy production. Annu Rev Entomol 45: 233-260.

Rypniewski WR, Perrakis A, Vorgias CE, Wilson KS (1994) Evolutionary divergence and conservation of trypsin. Protein Eng 7: 57-64.

Salomonsen J, Rathmann Sørensen M, Marston DA, Rogers SL, Collen T, van Hateren A, Smith AL, Beal RK, Skjødt K, Kaufman J (2005) Two CD1 genes map to the chicken MHC, indicating that CD1 genes are ancient and likely to have been present in the primordial MHC. Proc Natl Acad Sci USA 102: 8668-8673.

Salter-Cid L, Flajnik MF (1995) Evolution and developmental regulation of the major histocompatibility complex. Crit Rev Immunol 15: 31-75.

Salzet M, Tasiemski A, Cooper E (2006) Innate immunity in lophotrochozoans: the annelids. Curr Pharm Des 12: 3043-3050.

Samal B, Sun Y, Stearns G, Xie C, Suggs S, McNiece I (1994) Cloning and characterization of the cDNA encoding a novel human pre-Bcell colony-enhancing factor. Mol Cell Biol 14: 1431-1437.
Sato A, Mayer WE, Klein J (2003) A molecule bearing an immunoglobulin-like $V$ region of the CTX subfamily in amphioxus. Immunogenetics 55: 423-427.

Schluter SF, Bernstein RM, Marchalonis JJ (1997) Molecular origins and evolution of immunoglobulin heavy-chain genes of jawed vertebrates. Immunol Today 18: 543-549.

Schröder HC, Ushijima H, Krasko A, Gamulin V, Thakur NL, DiehlSeifert B, Müller IM, Müller WE (2003) Emergence and disappearance of an immune molecule, an antimicrobial lectin, in basal metazoa. A tachylectin-related protein in the sponge Suberites domuncula. J Biol Chem 278: 32810-32817.

Sekine H, Kenjo A, Azumi K, Ohi G, Takahashi M, Kasukawa R, Ichikawa N, Nakata M, Mizuochi T, Matsushita M, Endo Y, Fujita $\mathrm{T}$ (2001) An ancient Lectin-Dependent Complement System in an Ascidian: Novel Lectin Isolated from the Plasma of the Solitary Ascidian, Halocynthia roretzi. J Immunol 167: 4504-4510.

Shin DH, Webb B, Nakao M, Smith SL (2007) Molecular cloning, structural analysis and expression of complement component Bf/C2 genes in the nurse shark, Ginglymostoma cirratum. Dev Comp Immunol 31: 1168-1182.

Sillo A, Bloomfield G, Balest A, Balbo A, Pergolizzi B, Peracino B, Skelton J, Ivens A, Bozzaro S (2008) Genome-wide transcriptional changes induced by phagocytosis or growth on bacteria in Dictyostelium. BMC Genomics 9: 291.

Smith SL (1998) Shark complement: an assessment. Immunol Rev 166: 67-78.

Smith CL, DeLotto R (1992) A common domain within the proenzyme regions of the Drosophila snake and easter proteins and Tachypleus proclotting enzyme defines a new subfamily of serine proteases. Protein Sci 1225-1226.

Smith LC, Clow LA, Terwilliger DP (2001) The ancestral complement system in sea urchins. Immunol Rev 181: 16-34.

Smolenaars MM, Madsen O, Rodenburg KW, Van der Horst DJ (2007) Molecular diversity and evolution of the large lipid transfer protein superfamily. I Lipid Res 48: 489-502.

Söderhäll K, Cerenius L, Johansson MW (1994) The prophenoloxidase activating system and its role in invertebrate defence. Ann NY Acad Sci 712: 155-161.

Strickland DK, Ashcom JD, Williams S, Burgess WH, Migliorini M, Argraves WS (1990) Sequence identity between the $a_{2}$-macroglobulin receptor and low density lipoprotein receptor-related protein suggests that this molecule is a multifunctional receptor. I Biol Chem 265: $17401-17404$.

Sumimoto H (2008) Structure, regulation and evolution of Nox-family NADPH oxidases that produce reactive oxygen species. FEBS J. 275: 3249-3277.

Suzuki T, Shin-I T, Kohara Y, Kasahara M (2004) Transcriptome analysis of hagfish leukocytes: a framework for understanding the immune system of jawless fishes. Dev Comp Immunol 28: 993-1003.

Takezaki N, Figueroa F, Zaleska-Rutczynska Z, Klein J (2003) Molecular phylogeny of early vertebrates: monophyly of the agnathans as revealed by sequences of 35 genes. Mol Biol Evol 20: 287-292.

Tan MW, Ausubel FM (2000) Caenorbabditis elegans: a model genetic host to study Pseudomonas aeruginosa pathogenesis. Curr Opin Microbiol 3: 29-34.

Tang X, Xie M, Kim YJ, Zhou J, Klessig DF, Martin GB (1999) Overexpression of Pto activates defense responses and confers broad resistance. PlanT-cell 11: 15-29.

Tenor JL, Aballay A (2008) A conserved Toll-like receptor is required for Caenorhabditis elegans innate immunity. EMBO Rep 9: 103-109.

Thiel S, Vorup-Jensen T, Stover CM, Schwaeble W, Laursen SB, Poulsen K, Willis AC, Eggleton P, Hansen S, Holmskov U, Reid $\mathrm{KB}$, Jensenius JC (1997) A second serine protease associated with mannan-binding lectin that activates complement. Nature 386: 506510 .

Travis J (2009) On the origin of the immune system. Science 324: 580-582.

Trinité B, Voisine C, Yagita H, Josien R (2000) A subset of cytolytic dendritic cells in rat. I Immunol 165: 4202-4208.

Uinuk-Ool T, Maver WE, Sato A, Dongak R, Cooper MD, Klein J (2002) Lamprey lymphocyte-like cells express homologs of genes involved in immunologically relevant activities of mammalian lymphocytes. Proc Natl Acad Sci USA 99: 14356-14361.

Uinuk-Ool TS, Mayer WE, Sato A, Takezaki N, Benyon L, Cooper MD, Klein J (2003a) Identification and characterization of a TAPfamily gene in the lamprey. Immunogenetics 55: 38-48.

Uinuk-Ool TS, Takezaki N, Kuroda N, Figueroa F, Sato A, Samonte IE, Mayer WE, Klein J (2003b) Phylogeny of antigen-processing enzymes: cathepsins of a cephalochordate, an agnathan and a bony fish. Scand I Immunol 58: 436-448.

Utans U, Arceci RJ, Yamashita Y, Russell ME (1995) Cloning and characterization of allograft inflammatory factor-1: a novel macrophage factor identified in rat cardiac allografts with chronic rejection. I Clin Invest 95: 2954-2962.

Van Endert PM (1999) Genes regulating MHC class I processing of antigen. Curr Opin Immunol 11: 82-88. 
Van Leuven F, Cassiman JJ, Van den Berghe H (1978) Uptake and degradation of $\alpha_{2}$-macroglobulin-protease complexes in human cells in culture. Exp Cell Res 117: 273-282.

Varner J, Neame P, Litman GW (1991) A serum heterodimer from hagfish (Eptatretus stoutii) exhibits structural similarity and partial sequence identity with immunoglobulin. Proc Natl Acad Sci USA 88: 1746-1750.

Vasta GR, Ahmed H, Fink NE, Elola MT, Marsh AG, Snowden A, Odom EW (1994) Animal lectins as self/non-self recognition molecules. Biochemical and genetic approaches to understanding their biological roles and evolution. Ann N Y Acad Sci 712: 55-73.

Waddell DR, Duffy KT (1986) Breakdown of self/non-self recognition in cannibalistic strains of the predatory slime mold, Dictyostelium caveatum. J Cell Biol 102: 298-305.

Watts C, Powis S (1999) Pathways of antigen processing and presentation. Rev Immunogenet 1: 60-74.

Wiens M, Korzhev M, Krasko A, Thakur NL, Perović-Ottstadt S, Breter HJ,Ushijima H, Diehl-Seifert B, Müller IM, Müller WE (2005) Innate immune defense of the sponge Suberites domuncula against bacteria involves a MyD88-dependent signaling pathway. Induction of a perforin-like molecule. J Biol Chem 280: 27949-27959.

Whitham S, Dinesh-Kumar SP, Choi D, Hehl R, Corr C, Baker B (1994) The product of the tobacco mosaic virus resistance gene N: similarity to toll and the interleukin-1 receptor. Cell 78: 1101-1115.

Whitten MMA, Ratcliffe Norman A (1999) In vitro superoxide activity in the haemolymph of the West Indian leaf cockroach, Blaberus discoidalis. J Insect Physiol 45: 667-675.

Wiens M, Korzhev M, Perovic-Ottstadt S, Luthringer B, Brandt D, Klein S, Müller WE (2007) Toll-like receptors are part of the innate immune system of sponges (demospongiae: Porifera) Mol Biol Evol 24: 792-804.

Wiens M, Koziol C, Batel R, Müller WEG (1998) Phenylalanine hydroxylase from the sponge Geodia cydonium: implication for allorec- ognition and evolution of aromatic amino acid hydroxylases. Dev Comp Immunol 22: 469-478.

Wimmer W, Blumbach B, Diehl-Seifert B, Koziol C, Batel R, Steffen R, Müller IM, Müller WE (1999) Increased expression of integrin and receptor tyrosine kinase genes during autograft fusion in the sponge Geodia cydonium. Cell Adhesion Commun 7: 111-124.

Wölfle U, Martin S, Emde M, Schempp C (2009) Dermatology in the Darwin anniversary. Part 2: Evolution of the skin-associated immune system. J Dtsch Dermatol Ges 7: 862-869.

Xie K, Sowden MP, Dance GS, Torelli AT, Smith HC, Wedekind JE (2004) The structure of a yeast RNA-editing deaminase provides insight into the fold and function of activation-induced deaminase and APOBEC-1. Proc Natl Acad Sci USA 101: 8114-8119.

Yeh FC, Wu SH, Lai CY, Lee CY (2006) Demonstration of nitric oxide synthase activity in crustacean hemocytes and anti-microbial activity of hemocyte-derived nitric oxide. Comp Biochem Physiol B Biochem Mol Biol 144: 11-17.

Young L, Leonhard K, Tatsuta T, Trowsdale J, Langer T (2001) Role of the ABC transporter Mdl1 in peptide export from mitochondria. Science 291: 2135-2138.

Zanetta JP, Vergoten G (2003) Lectin domains on cytokines. Adv Exp Med Biol 535: 107-124.

Zarkadis IK, Mastellos D, Lambris JD (2001) Phylogenetic aspects of the complement system. Dev Comp Immunol 25:745-762.

Zasloff M (2002) Antimicrobial peptides of multicellular organisms. Nature 415: 389-395.

Zhang F, Zhang W, Liu L, Fisher CL, Hui D, Childs S, DoroviniZis K, Ling V (2000) Characterization of ABCB9, an ATP binding cassette protein associated with lysosomes. J Biol Chem 275: 2328723294. 